\title{
GRAN ESTRATEGIA EN CHINA, ESTADOS UNIDOS Y RUSIA ${ }^{1}$
}

\section{$\mid 15$}

\author{
Carlos Enrique Álvarez Calderón \\ Andrés Eduardo Fernández Osorio
}

\section{Introducción}

Una de las discusiones epistémicas más interesantes en los estudios de seguridad y defensa en la actualidad trata acerca de si los Estados tienen, realmente, una gran estrategia que guíe su pensamiento estratégico en la formulación de políticas exteriores y de seguridad que permitan el cumplimiento de los intereses nacionales. Algunos, como Swaine (2000), consideran que no, pues argumentan que, al constituirse como actores fragmentados, los Estados son propensos a los cismas domésticos que impiden efectivamente cualquier búsqueda racional y coherente del interés nacional (incluso podrían llegar a impedir alcanzar un consenso significativo acerca de cuáles serían dichos intereses nacionales).

Sin embargo, los autores de este capítulo considerarían que en países como China, Rusia y los Estados Unidos, a pesar de que la toma de decisiones políticas internas involucra a múltiples actores (muchos de los cuales están, con frecuencia, motivados por sus propios intereses particulares), la existencia de una gran estrategia no solo sería posible, sino que, de hecho, podría existir.

Como muchas investigaciones académicas en el ámbito de los estudios de seguridad y defensa, este capítulo hace varias suposiciones importantes acerca de la gran estrategia, enraizadas en la tradición intelectual de la teoría del realismo clásico de las relaciones internacionales (Lobell et al., 2008; Dufort, 2017; Serrano Álvarez, 2018), como la naturaleza anárquica del sistema internacional, la natu-

1 Este capítulo del libro hace parte del Proyecto de Investigación de la Maestría en Seguridad y Defensa Nacionales, titulada "Desafíos y Nuevos Escenarios de la Seguridad Multidimensional en el Contexto Nacional, Regional y Hemisférico en el Decenio 2015-2025”, que hace parte del Grupo de Investigación Centro de Gravedad de la Escuela Superior de Guerra "General Rafael Reyes Prieto", reconocido y categorizado en (A) por Colciencias, con el código COL0104976. 
raleza esencialmente competitiva de la política internacional, la importancia del poder y la consecución de los intereses nacionales. Si se toma en cuenta todo lo anterior, los Estados serían actores relativamente racionales que buscarían satisfacer sus intereses nacionales en el sistema internacional, de acuerdo con sus capacidades de poder. En este sentido, la gran estrategia de un Estado proporcionaría la orientación estratégica, que impulsaría su comportamiento de política exterior y de seguridad, para alcanzar dichos intereses nacionales.

Goldstein (2005) definió la gran estrategia como "la combinación distintiva de medios militares, políticos y económicos mediante los cuales un Estado busca asegurar sus intereses nacionales" (p. 17). A este respecto, Posen (1986) señaló que

una gran estrategia es una cadena político-militar de medios y fines, la teoría de un Estado sobre cómo puede "generar" la seguridad para sí misma. Idealmente, incluye una explicación de por qué se espera que la teoría funcione. Una gran estrategia debe identificar las posibles amenazas a la seguridad del Estado y debe idear soluciones políticas, económicas, militares y de otro tipo para esas amenazas. Las prioridades deben establecerse tanto entre las amenazas como entre las soluciones, ya que dado un entorno internacional anárquico, la cantidad de amenazas posibles es numerosa y, dados los límites ineludibles de una economía nacional, los recursos son escasos [...]. Por supuesto, las grandes estrategias casi nunca se expresan en una forma tan rigurosa, pero el analista puede guiarse por esta conceptualización en su intento de descubrir la gran estrategia del Estado. (p. 13)

Como sugieren las definiciones anteriores, los intereses nacionales tienden a estar en el centro de cualquier gran estrategia. Es decir, los Estados poseen una gran estrategia a partir de la comprensión de sus intereses nacionales y persiguen estos intereses de acuerdo con el orden de sus preferencias, dadas las limitaciones sistémicas del entorno internacional al cual podrían llegar a verse enfrentados. No obstante, "los Estados líderes generalmente han tratado de moldear, y no solo de sobrevivir, en su entorno internacional, por lo general de formas que mejorarán aún más su riqueza, poder y estatus" (Goldstein, 2005, p. 17). Además, la gran estrategia tendería a proporcionar un ordenamiento aproximado de las preferencias del Estado (dada la escasez de recursos nacionales para perseguir estas preferencias).

Por lo tanto, las grandes estrategias incluirían un orden de preferencias, en el cual los Estados estarían dispuestos a hacer concesiones cuando las metas entran en conflicto o cuando los medios para alcanzarlas son limitados. Dichas concesiones se basarían en un conjunto de prioridades relativas para el Estado. Según Norris (2016), dados los diversos niveles de permisividad en el sistema internacional (así como los distintos niveles de limitaciones relativas de las capacidades de un Estado), 
un Estado con mayores capacidades de poder podría llegar a perseguir intereses secundarios e incluso terciarios, mientras que algunos Estados con un poder limitado tendrían dificultades incluso para satisfacer un mínimo de intereses nacionales vitales.

En resumen, la gran estrategia de un Estado sería una lógica estratégica racional que identificaría los objetivos nacionales y diseñaría políticas para lograr su consecución, en consideración de las dinámicas del sistema internacional y las capacidades de poder del propio Estado. Un aspecto fundamental de la gran estrategia de un Estado sería el filtro político interno que debería interpretar tanto el sistema internacional como los propios intereses y capacidades del Estado. Esto implicaría cierta comprensión de la política interna de un Estado para estudiar con precisión su gran estrategia, ya que estas condiciones políticas internas desempeñarían un papel clave a la hora de determinar cómo los Estados perciben e interpretan su entorno internacional, así como el lugar y papel a ocupar en dicho ecosistema.

\section{La gran estrategia de China}

Habría cuatro condiciones principales que influyen en el diseño de la gran estrategia de la República Popular de China. Primero, el Partido Comunista Chino (PCC) estaría en control del gobierno y de los nervios del poder estatal; además, el PCC definiría los intereses nacionales e implementaría la gran estrategia de China. En este sentido, la preservación del control absoluto del poder estatal chino por parte del PCC sería una preocupación principal contemplada en la gran estrategia, pues uno de los factores clave de legitimación del PCC sería la preservación del crecimiento económico continuo que ayuda a garantizar la estabilidad interna (Guo, 2013). Además, la interacción económica de China en el plano internacional ayudaría a allanar el camino para su ascenso a la categoría de gran potencia, por lo que la economía ocuparía un lugar destacado en la gran estrategia de China. Por ende, el pensamiento y la cultura estratégica en seguridad y defensa, así como la definición de los intereses de China en la actualidad, y en el futuro previsible, estaría dominada por el PCC. En otras palabras, la alta dirección del pCC determinaría los intereses nacionales, por lo que, en palabras de Knorr (1975), al definir estos intereses, los intereses del Estado a menudo se combinarían con los intereses del partido. Este tipo de contubernio daría lugar al uso del término "Partido de Estado", para describir la moderna política de China, en la cual sus intereses nacionales estarían, a menudo, atados a las preferencias del PCC proyectadas como intereses nacionales del Estado (Li, 2010). 
Segundo, muchos de los resultados de las políticas públicas en la República Popular de China serían producto de una competencia doméstica entre facciones, que tomaría al menos dos formas: 1) la división de base ideológica y 2) la competencia burocrática. Con relación a la primera, tales divisiones ideológicas a menudo se manifestarían como facciones personalistas que compiten entre sí y que tenderían a compartir perspectivas, antecedentes y valores ideológicos comunes (como la facción de la Liga Juvenil Comunista, la camarilla de Shanghái o la banda de los "principitos"). ${ }^{2}$ Sería pertinente distinguir entre tales fuentes ideológicas de fricción política interna y las luchas burocráticas por el poder y la influencia, que a menudo provendrían de la rivalidad institucional entre entidades del Estado (como, por ejemplo, el Ministerio de Finanzas versus la Comisión Nacional de Desarrollo y Reforma).

En la práctica, las diferencias ideológicas podrían llegar a traslaparse en competencias burocráticas; por ejemplo, la camarilla de Shanghái podría estar representada de manera desproporcionada en el Ministerio de Finanzas o la facción de la Liga Juvenil Comunista podría dominar el Ministerio de Industria y Tecnología de la Información. Es decir, el poder de la facción ideológica podría reflejarse y complementarse con dinámicas burocráticas institucionales. Sin embargo, en teoría, los dos constituirían fuentes conceptualmente distintas de fuerzas políticas internas que darían forma a los intereses nacionales y la gran estrategia de China. En consecuencia, y para la mayoría de las decisiones, el secretario general del PCC ahora tendría que consultar y forjar el consenso entre los líderes superiores y los actores clave del sistema político de China (Guo, 2013). Los actores clave serían, por lo general, la élite estratégica representada por los jefes de los diversos xitong (centros de poder organizacionales e institucionales dentro del sistema político chino). ${ }^{3} \mathrm{La}$

2 La Liga Juvenil Comunista (LGC) ha sido guiada por el expresidente Hu Jintao y los cuadros filiados a ella forman un bloque más grande entre los veinticinco miembros del Politburó surgido en el $18^{\text {vo }}$ Congreso del PCC en 2012. Los miembros de la LGC eran fuertes, sobre todo en las regiones, tanto que se decía que Hu Jintao usaba una táctica de "asediar al centro con las regiones", en contraste con las tendencias del expresidente Jiang Zemin, que guiaba la camarilla de Shanghái. Después de haber hecho todo lo que estaba a su alcance para eclipsar a las facciones de la LGC y la camarilla de Shanghái, el actual presidente, Xi Jinping, ha invertido importantes esfuerzos para elevar su propia facción, cuyo componente fundamental sería la camarilla de Zheijiang. Así como Jiang Zemin preparó la facción de Shanghái, así Xi ha promovido cuadros que habían servido bajo su dirección, cuando era secretario del partido en Zhejiang, de 2002 a 2007. Otros componentes de la facción de Xi Jinping comprenden la banda de los "principitos" y la camarilla de Shaanxi (miembros que han servido en la provincia de nacimiento de $\mathrm{Xi}$ ).

3 Ejemplos de tales organizaciones incluyen a otros miembros del Comité Central del Politburó, el Consejo de Estado y la Comisión Militar Central, el Ministerio de Finanzas, el Banco Popular de China, los diversos bancos de políticas (Banco de Desarrollo de China, Importación y Exportación de China Banco, etc.), el Ministerio de Comercio, Comisión Nacional de Desarrollo y Reforma, los cuatro grandes bancos chinos, entre otros. 
membresía en este grupo altamente personalista sería dinámica y fluctuaría con el tiempo, a medida que las influencias personales subiesen o bajasen. Los intereses de estos jugadores tampoco serían estáticos, aunque siempre se caracterizarían por búsquedas pragmáticas en intereses particulares y la maximización del poder, por lo que, independientemente de las motivaciones específicas, el comportamiento resultante de la política exterior de China a menudo se caracterizaría por aparentes incoherencias, inconsistencias o vacilaciones en el comportamiento "estratégico" en el sistema internacional, como un Estado-nación (Ardila Castro \& Rodríguez, 2018).

Tercero, el PCC estaría organizado jerárquicamente (figura 1), en esta organización la posición de secretario general ocuparía la cúspide de la pirámide; si bien el poder en China estaría menos centralizado de lo que era bajo el periodo de Mao Tse-Tung, la autoridad última aún se encontraría en manos del secretario general. En efecto, y según sea necesario y cuando lo considere oportuno, el secretario general del PCC intervendría en las decisiones que, de lo contrario, podrían ser objeto de fricciones internas; en este orden de ideas, una vez que el secretario general da órdenes, las facciones harían su trabajo con una mínima resistencia pasiva en los márgenes.

De acuerdo con Norris (2016), la lógica de tal comportamiento no sería difícil de comprender, ya que demasiada resistencia pasiva por parte de un individuo, facción o entidad burocrática, podría atraer la atención no deseada de entidades más poderosas dentro de un sistema fuertemente jerárquico, lo que generaría como resultado la marginación, el aislamiento, la purga o incluso la eliminación total (como sucedería actualmente en la política doméstica en China). Por lo tanto, podría asumirse que China se comportaría, en general, como un actor racional unitario en asuntos de interés estratégico en el sistema internacional; es decir, China generalmente se comprometería con la búsqueda racional de sus intereses nacionales como una sola entidad en el escenario internacional. ${ }^{4}$

El cuarto aspecto del sistema político chino que influiría en su gran estrategia sería la creciente complejidad del sistema internacional contemporáneo, ya que operar en un mundo tecnológico donde la información fluye rápidamente ha requerido el retorno de la toma de decisiones a niveles más bajos de la jerarquía. Aunque la secretaría general del PCC sería la posición más importante en el aparato político y estaría investida de la máxima autoridad, todavía el secretario general tendría que confrontar la realidad de la limitación humana con respecto al tiempo y

4 Por supuesto, ningún Estado sería perfectamente "racional" ni "unitario", dadas las realidades de la política interna y la multitud de otros factores que configuran el comportamiento internacional. 


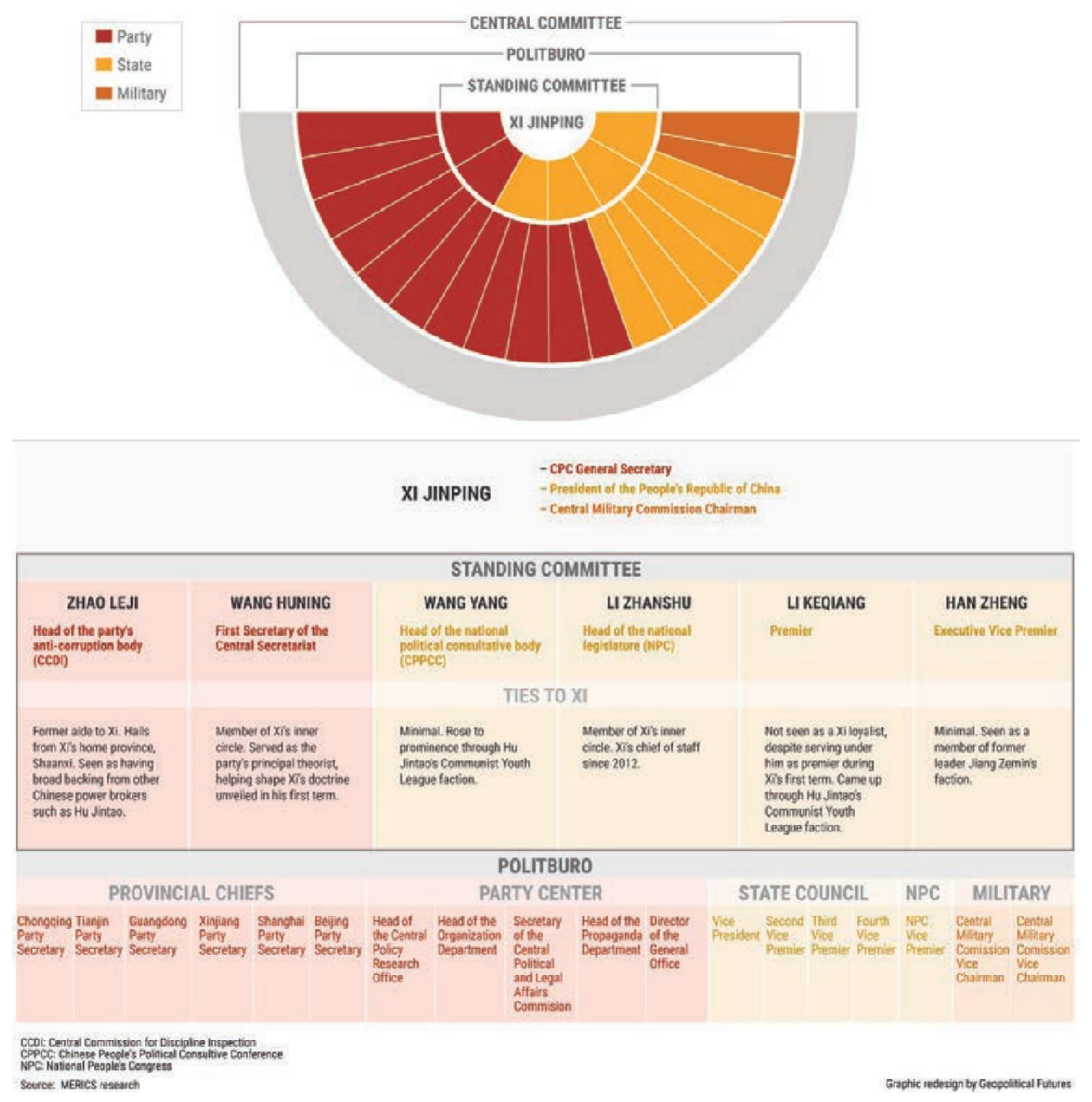

Figura 1. Estructura de poder en China.

Fuente: Geopolitical Futures (2018).

el procesamiento de un gran volumen de información. Esta limitación humana sería la principal razón por la que los líderes chinos deben confiar (en cierta medida), en una infraestructura de apoyo burocrático para ayudar a tomar decisiones y liderar el complejo aparato administrativo que gobierna China; este ha sido el caso desde los tiempos imperiales, cuando China desarrolló las primeras innovaciones en la administración civil. 


\subsection{Los intereses nacionales objetivos de China}

Con base en lo anterior, a la hora de definir los intereses nacionales y la implementación de la gran estrategia de China, el secretario general del PCC emitiría principios estratégicos de alto nivel (muchos los cuales se hacen públicos cuando se dirige formalmente al Congreso Nacional del Pueblo); ${ }^{5}$ estos pueden ser vagos y tenderían a variar de manera sutil con el tiempo, a través de cambios matizados en la retórica. Dichos principios estratégicos ofrecerían poco en cuanto a aspectos específicos, pero en cambio destacarían los intereses nacionales objetivos y los intereses subjetivos del liderazgo de turno. ${ }^{6}$ Estas declaraciones del secretario general usualmente se expresarían mediante lemas, frases de moda y otras generalidades, pero ofrecerían una importante orientación para los niveles más bajos del aparato de implementación y toma de decisiones de la política pública en China. Por lo tanto, las evaluaciones generales del entorno estratégico internacional de China, desarrolladas por la secretaria general del PCC, proporcionarían la "intención del comandante" para el resto de la cadena de mando.

Un ejemplo de dicha guía (frases, lemas, entre otros) incluyó el tema de la "estabilidad" como una prioridad orientadora para la administración pasada de $\mathrm{Hu}$ Jintao y Wen Jiabao, así como el "ascenso pacífico", la "diplomacia gana-gana”, el "desarrollo científico" y la "sociedad armónica". " En la actualidad, Xi Jinping también habría presentado el concepto de "nuevo estilo del relacionamiento entre grandes potencias", como un marco para las relaciones sino-estadounidenses. Por ende, este tipo de orientación de alto nivel determinaría la estrategia que perseguiría el xitong específico, quien traduciría estos principios generales de orientación en políticas nacionales más específicas, a lo largo de los diversos canales de gobierno. Así mismo, este proceso representaría un camino a través del cual los intereses de los actores subestatales influirían y obtendrían acceso en la configuración de la perspectiva estratégica más amplia de China como actor en el escenario internacional. ${ }^{8}$

5 Esta guía de alto nivel serviría como el equivalente a las ideas y los principios encontrados en la Estrategia de Seguridad Nacional de los Estados Unidos.

6 Para comprender las particularidades de los intereses nacionales objetivos y subjetivos, ver capítulo II.

7 Con relación a la orientación de la política exterior china, conocida como la teoría del "ascenso pacífico" (heping jueqi), el propósito era declarar la intención del ascenso internacional de China en la jerarquía internacional de los poderes, pero sin poner en cuestión, desafiar o incluso perturbar el orden internacional existente. El "auge pacífico" rechazaría la noción de la competencia por los recursos, el pillaje de los mismos y las guerras de agresión (como en el caso de Alemania durante la Primera Guerra Mundial y de Japón en la Segunda Guerra Mundial), así como la "mentalidad de la guerra fría", basada en la confrontación ideológica, que sucedería entre la Unión Soviética y los Estados Unidos. Posteriormente, en consideración a que el término de "ascenso" podría causar prevención en el sistema internacional, China adoptaría el eslogan del "desarrollo pacífico" (hepingfazhan).

8 Por supuesto, los actores del sub-Estado podrían ser propensos a interpretar la guía del alto nivel para maximizar sus propios intereses burocráticos o ideológicos, lo que generaría fricciones dentro del sistema sobre cuales elementos de una política nacional merecerían una mayor prioridad. 
Este proceso llevaría luego a la implementación de estrategias y políticas particulares sobre un tema en específico, a menudo por los actores relevantes de la organización del sub-Estado. El hecho de que la dirigencia del PCC deba confiar en los niveles inferiores, en la interpretación e implementación de la estrategia, no significaría que China carezca de una gran estrategia; más bien, cuanto más importante sea un tema para la dirigencia, mayor atención tendría el liderazgo del PCC para abordar ese problema. Asimismo, el liderazgo del PCC tendería a proporcionar una orientación más específica y desempeñaría un papel más directo en la implementación de políticas que se considerarían demasiado importantes como para confiarlas a la interpretación y la implementación de los niveles más bajos del sistema burocrático; por ejemplo, luego de anunciar por primera vez la política del "Nuevo Cinturón Económico de la Ruta de la Seda" en el 2013 (para vincular a China con Europa a través de Asia Central), Xi Jinping se encargó de elaborar los mecanismos de implementación de dicha estrategia. Es decir, el liderazgo del PCC guiaría e implementaría todo si pudiera, pero, por desgracia, reconocería los límites materiales que enfrentaría a la luz de la creciente complejidad y velocidad de la información en el sistema que administra. Por ende, el pragmatismo de la dirigencia de China reconocería que solo tiene la posibilidad de enfocar su tiempo y sus recursos en los asuntos más importantes.

La noción de "importancia” estaría determinada por varios atributos. Primero, si un problema llegará a amenazar la supervivencia del PCC (por ejemplo, asuntos relacionados con el malestar interno causados por tensiones étnicas, desempleo o protestas populares) representaría amenazas particulares para el régimen. Del mismo modo, temas relacionados con la integridad territorial de China y Taiwán también tendrían una atención prioritaria (figura 2), así como el desempeño de la economía china. Por supuesto, los intereses nacionales subjetivos de la dirigencia del PCC también cobrarían importancia; por ejemplo, la desigualdad, el desarrollo provincial del interior del país y la innovación china fueron todas prioridades de la administración de $\mathrm{Hu}$ Jintao y Wen Jiabao, mientras que las disputas territoriales marítimas, la campaña anticorrupción y la guerra comercial con los Estados Unidos serían las prioridades de Xi Jinping. Otra característica que exigiría la atención de los líderes chinos es la propensión a que un tema determinado genere controversia internacional para China, como el papel de China en Sudán o Venezuela.

El principal interés nacional objetivo que guiaría la actual gran estrategia de la República Popular de China, es el mantenimiento del control de China por parte del PCC. En efecto, varios académicos (Gill, 2007; Goldstein, 2005; Yizhou, 2007; Bergsten et al., 2008), han identificado la estabilidad del régimen como el prin- 


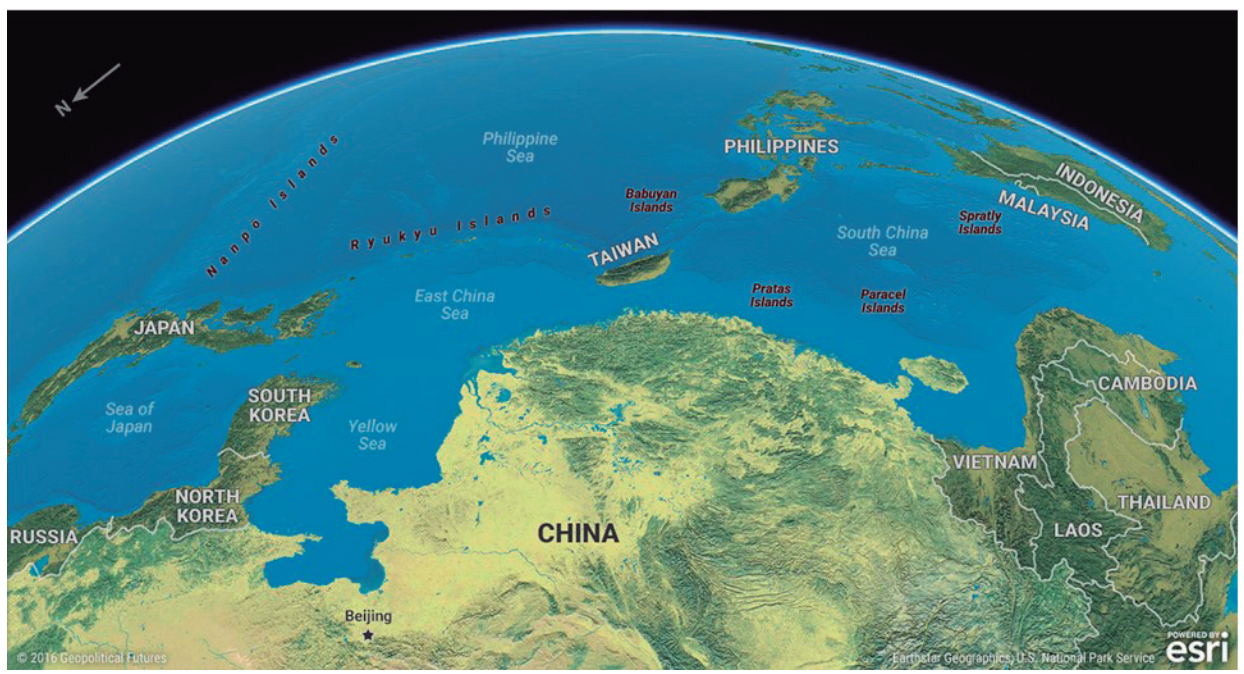

Figura 2. Perspectiva geopolítica de China.

Fuente: Geopolitical Futures (2018).

cipal objetivo estratégico de China. No obstante, el control del PCC sobre China descansaría en su legitimidad; desde el inicio del periodo de "Reforma" y "Apertura" (Gaige y Kaifang), en 1978, las bases de la legitimidad interna del PCC se habrían trasladado del maoísmo revolucionario hacia el pragmatismo económico. De hecho, la economía es tanto un fin para legitimar el régimen como un medio para lograr los intereses estratégicos del Estado, por lo que el crecimiento económico habría venido a reemplazar la ideología comunista como la principal dinámica que legitima la credibilidad popular del PCC. En este sentido, Kong (2010) afirma que "una consecuencia profunda de la reforma y apertura de China es que la ideología comunista ha perdido su atractivo y el crecimiento económico se ha convertido en el principal legitimador y estabilizador del sistema político chino" (p. 141), tanto así que el crecimiento económico se fusionó con la seguridad nacional y la estabilidad del régimen en curso (Zhengyi, 2004).

En la actualidad, el PCC mantendría su mandato de gobernar gracias a la capacidad de proporcionar tasas sostenidas de crecimiento económico durante los últimos cuarenta años. Pero a medida que ese crecimiento se desacelere (aún más con la actual guerra comercial con los Estados Unidos) el PCC podría buscar gradualmente sustituir el crecimiento económico por el nacionalismo en su narrativa legitimadora. Si durante el liderazgo de Hu Jintao se enfatizó en la "estabilidad" como una de las bases más importantes para la preservación del dominio del PCC, Xi Jinping ha abogado más por el sentimiento nacionalista (en parte para diferen- 
ciarse de su predecesor), como lo demuestra una política más firme de China con respecto a sus reclamaciones territoriales en el Mar de China Meridional.

Después de haber asegurado el régimen, el segundo interés nacional objetivo de China sería el de maximizar su capacidad en la configuración de su entorno regional y global. A nivel internacional, el compromiso de China con la economía mundial proporcionaría beneficios significativos en forma de mano de obra barata y acceso a un gran mercado potencial, lo que haría de China un socio atractivo; ambos beneficios reforzarían la legitimidad del régimen y mostrarían a los socios internacionales los beneficios de la creciente estatura estratégica de China, pero de una manera que asegura a sus vecinos su intención pacífica y de beneficio mutuo (Gill, 2007). En efecto, ese sería uno de los principales objetivos de las iniciativas del "Cinturón Económico de la Ruta de la Seda" y la "Ruta de la Seda Marítima" propuestas por Xi Jingping, que beneficiarían a sesenta países, que albergarían en total el 75\% de las reservas energéticas, el 70\% de la población y el 55\% del Producto Interno Bruto (рів) del mundo (figura 3).

Al moldear proactivamente su entorno internacional, China podría crear condiciones propicias para la realización de sus intereses nacionales; para tal efecto, "la nueva diplomacia de seguridad busca contrarrestar, cooptar o eludir lo que

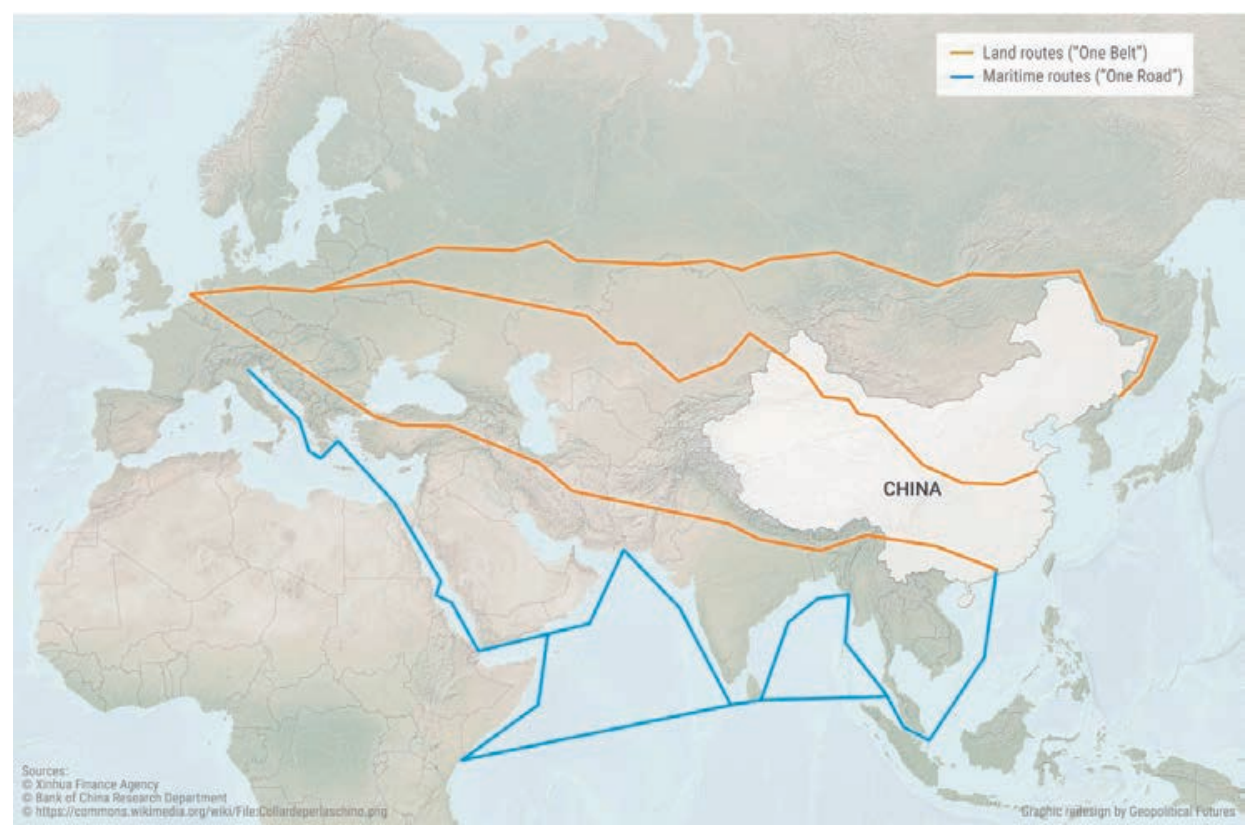

Figura 3. Las nuevas rutas de la seda de China. Fuente: Geopolitical Futures (2018). 
China percibe como excesiva influencia norteamericana en la periferia china, mientras evita una confrontación abierta con Estados Unidos, todo con el objetivo de configurar su propio entorno de seguridad" (Gill, 2010, p. 10). Por ende, mientras China alcanza el estatus de gran potencia o "poder nacional global" (zhonghe guoli), seguirá buscando mantener un entorno regional y global más permisivo en el que pueda ejercer sus crecientes capacidades de poder y ascender sin restricciones en la jerarquía internacional de los poderes. No obstante, uno de los asuntos más importantes que tendría en cuenta el Estado chino podría ser la estrategia del adversario, es decir, cuál sería la estrategia de contención ${ }^{9}$ de los Estados Unidos frente a una mayor proyección de influencia de China en el sistema internacional. Como resultado, China buscaría evitar a toda costa la formación de una potencial coalición de Estados (balancing coalition) que se oponga al creciente poder de China (Medeiros, 2007). Para Goldstein (2005), este interés nacional objetivo dataría de 1996, cuando los altos cargos chinos reevaluaron la utilidad del uso de la fuerza por parte de China y se embarcaron en un nuevo camino de reafirmación regional y global. Desde entonces, habría surgido un consenso sobre la gran estrategia de China entre sus líderes:

La gran estrategia apunta a diseñar el ascenso de China a un estatus de gran potencia, dentro de las limitaciones de un sistema internacional unipolar que domina Estados Unidos. Está diseñado para mantener las condiciones necesarias para continuar con el programa de modernización económica y militar de China, así como para minimizar el riesgo de que otros, sobre todo Estados Unidos, vean el aumento continuo en las capacidades de China como una amenaza inaceptablemente peligrosa que debe ser detenido o quizás impedido. En resumen, la gran estrategia de China apunta a aumentar la influencia internacional del país, sin desencadenar una reacción de contrapeso estratégico. (Goldstein, 2005, p. 12)

El interés de evitar una coalición de Estados en su contra y tranquilizar a otros actores regionales y globales, sería la fuerza impulsora detrás de gran parte de los compromisos regionales de China, así como de sus esfuerzos multilaterales como potencia media; este esfuerzo tendría como objetivo crear vínculos que hagan de China un actor indispensable o, al menos, muy atractivo, cuyos intereses no deberían ser obstaculizados por los actores clave del sistema. China también estaría tratando de consolidar su reputación como una potencia responsable en el sistema internacional, como parte de su esfuerzo por tranquilizar a otros Estados que temen 
a una China más poderosa; en este contexto, las capacidades de poder económicas se convertirían en instrumentos críticos para el logro de dichos objetivos estratégicos.

Otro interés nacional objetivo de China sería el de diversificar su acceso a las fuentes de energía y otros recursos naturales (Medeiros, 2007). La lógica detrás de este interés se debería a la vulnerabilidad china ante una gran dependencia de insumos energéticos y materias primas importadas para una economía en crecimiento; tanto así, que en el pensamiento estratégico chino se utilizaría con frecuencia el término "seguridad económica" (jingji anquan) en los documentos estratégicos en seguridad y defensa (CICIR, 2005). En consecuencia, y como un esfuerzo por minimizar la exposición a una sola fuente de recursos naturales, China habría venido buscando activamente diversificar su abastecimiento en regiones como África o América Latina. Por último, un interés nacional objetivo de China sería el de limitar la capacidad de actuación internacional de Taiwán. Ello se remonta a las primeras políticas exteriores de la República Popular de China y continuaría siendo un importante motor de los intereses estratégicos de China, ya que Taiwán y otras cuestiones de integridad territorial tenderían a ser temas muy sensibles para la alta dirigencia del PCC. Esto sería, en parte, una función de la historia, ya que China consideraría su historia como una basada en ciclos dinásticos; ${ }^{10}$ las causas inmediatas del declive dinástico podrían ser atribuidas a la corrupción y la mala administración, así como a la conquista por parte de una potencia externa. En este orden de ideas, una de las señales históricas de un régimen débil sería la pérdida de territorio periférico que se considera parte del imperio; por lo tanto, debido a que la preservación del régimen sería un interés nacional vital, y se entendería que la falta de integridad territorial podría ser un presagio del declive del régimen, temas como el de Taiwán son un asunto sensible para el PCC.

\subsection{La relación entre los imperativos geopolíticos y los intereses nacionales de China}

Los imperativos geopolíticos de China guardarían una estrecha relación con sus intereses nacionales objetivos más prioritarios. Si se retoman los principales imperativos geopolíticos de China contemplados en el capítulo $\mathrm{x}$ de este volumen, se encontrarían varios supuestos de la cultura y pensamiento estratégico en segu-

10 De acuerdo a Guo (2013), un fuerte conquistador uniría las tierras de China en un imperio; este conquistador se convertiría entonces en emperador y se establecería una dinastía que duraría cierto período de tiempo. Los símbolos de la civilización china (dinastías Tang, Ming y Song) florecieron cuando el imperio era fuerte y estaba bien gobernado; pero eventualmente surgirían fisuras que anunciarían el principio del fin de una dinastía. Posteriormente, el colapso dinástico introduciría un período caótico de territorios gobernados por "seńores de la guerra", a menudo plagados de bandidaje. Eventualmente, una conquista externa o un "señor de la guerra” indígena consolidaría nuevamente el imperio, comenzando así una nueva dinastía. 
ridad y defensa de China que moldearían su gran estrategia. Los dos primeros imperativos geopolíticos de China (protección del núcleo vital y control de las zonas buffers) corresponderían a sus dos principales intereses nacionales. Como ya se ha expresado, la línea de 15 pulgadas (figura 4) marcaría la frontera entre estas dos regiones geopolíticas, ya que la gran mayoría de la población viviría al este y al sur de esta línea, un núcleo vital más pequeño que el de los Estados Unidos y en donde habitarían mayoritariamente chinos de la etnia Han.

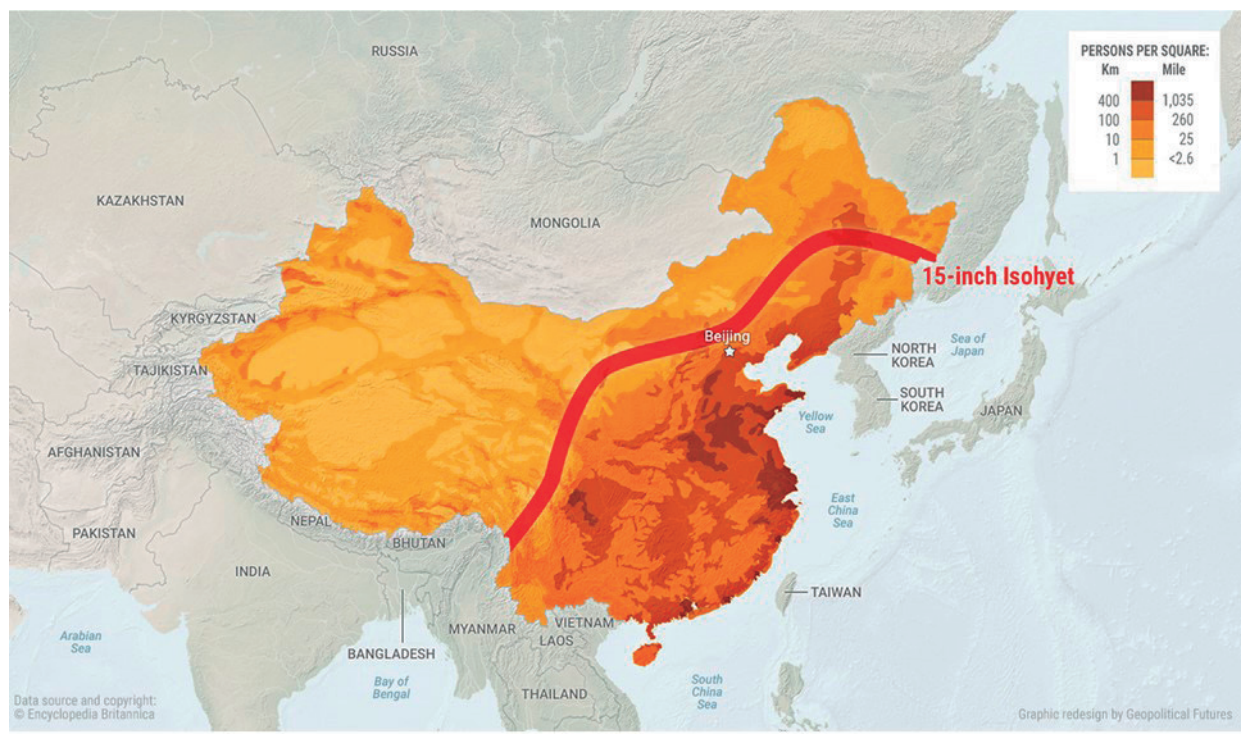

Figura 4. Línea de las 15 pulgadas.

Fuente: Geopolitical Futures (2018).

No obstante, el punto más vulnerable de China sería su costa, por lo que la mayor amenaza militar para China provendría de la Marina de los Estados Unidos, ya que esta tendría la capacidad para bloquear los pasos estratégicos y puertos que conformarían las líneas de comunicación marítima, a través de las cuales China se provee de materias primas y recursos energéticos, como, por ejemplo, del Estrecho de Ormuz (figura 5). En caso de que Estados Unidos lo llegase a hacer, ello supondría paralizar económicamente a China. Además, Taiwán estaría posicionado de tal manera que puede servir fácilmente como una base naval y aérea que podría cercar el movimiento marítimo entre el Mar del Sur de China y el Mar de China Oriental, lo que dejaría aislada la costa del norte de China y Shanghái. Por ende, los imperativos geopolíticos tercero y cuarto de China guardarían relación con sus intereses nacionales objetivos ubicados en tercer y cuarto lugar. 


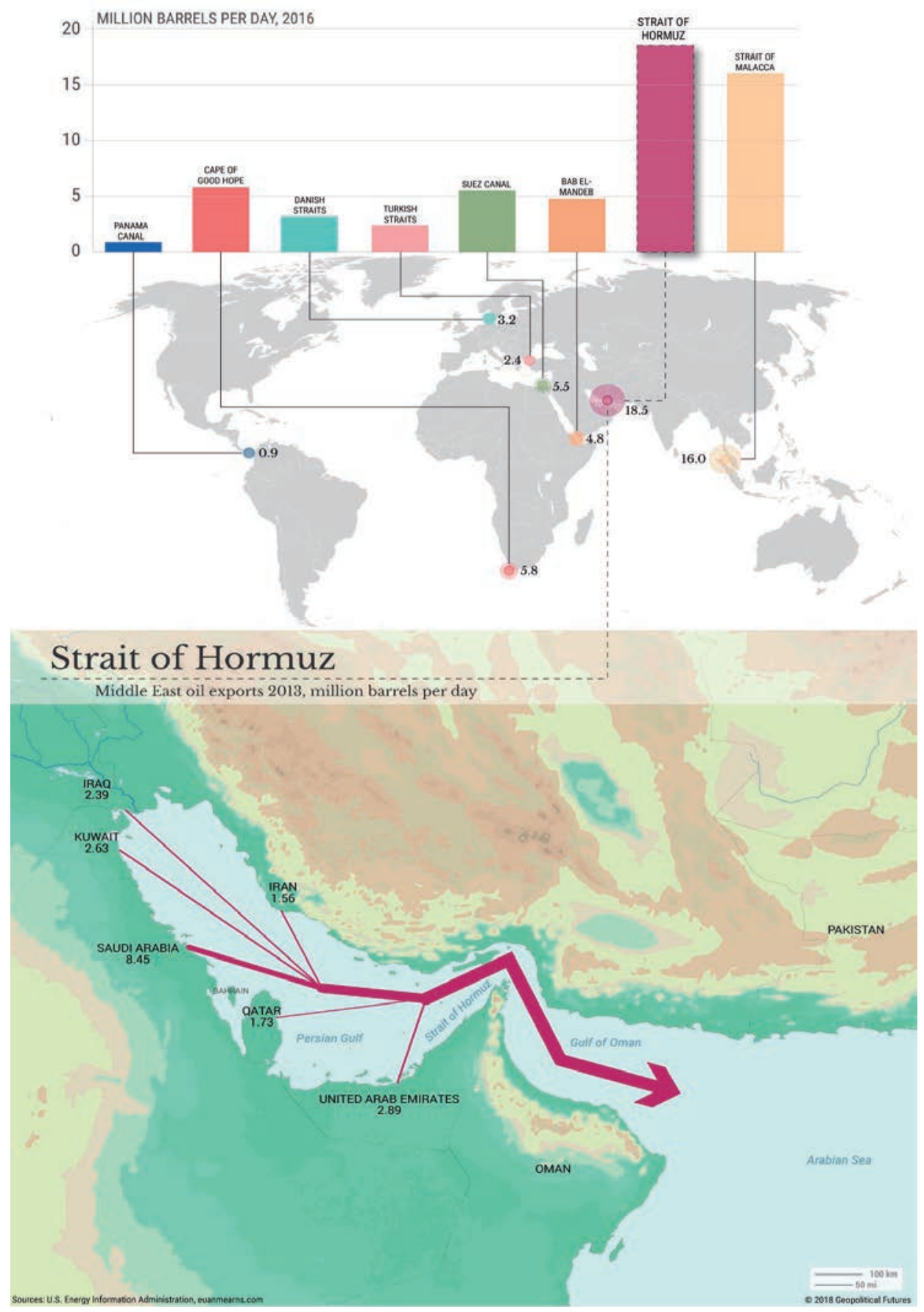

Figura 5. Líneas de comunicación marítima del petróleo.

Fuente: Geopolitical Futures (2018). 
Es decir, el problema geopolítico de China sería económico; su primer imperativo geopolítico (mantener la unidad de Han China), su tercer imperativo (proteger la costa) y su cuarto imperativo (proteger las rutas, recursos y mercados estratégicos) estarían afectados más por consideraciones económicas, que por consideraciones militares. Asimismo, sus problemas políticos internos y externos se desprenderían de la economía; por lo que el espectacular desarrollo económico de la última generación ha sido, en gran medida, geográfico, lo que ha beneficiado al núcleo vital chino y ha dejado al resto del interior en una situación de pobreza y atraso.

\section{La gran estrategia de la Federación de Rusia}

Históricamente, la naturaleza de las instituciones políticas y militares rusas ha cimentado una estrecha interrelación en la definición de los intereses nacionales y la utilización del poder militar para la materialización de sus ideales. La existencia de una marcada centralización política, herencia de los tiempos imperiales y soviéticos, así como una profunda integración entre la sociedad y las Fuerzas Militares, habría permitido la existencia de un entendimiento generalizado sobre los objetivos del Estado y la importancia de la proyección de poder más allá de las fronteras nacionales. En efecto, durante la Guerra Fría el poder militar y, en especial, los acuerdos de cooperación científica militar, sirvieron a la Unión de Repúblicas Socialistas Soviéticas (URSS) para fortalecer su política exterior y contribuir a la defensa de sus intereses en diferentes regiones del mundo. Esta tendencia se habría mantenido en la Federación de Rusia, donde a través de las ventas de sistemas de armamento a países extranjeros y la participación en misiones internacionales se habría fortalecido la imagen nacional y reafirmado la férrea voluntad de defender los intereses nacionales, mostrando así los límites hasta los cuales estaría dispuesto a llegar el Kremlin para consolidar nuevamente a Rusia como una gran potencia.

Los puntos de vista fundamentales de Rusia en política pública de seguridad y defensa, así como su pensamiento estratégico, se encontrarían en la Estrategia de Seguridad Nacional de Rusia hasta el año 2020 (publicada en mayo del 2009 y actualizada en el 2015), así como en las Doctrinas Militares de 2010 y 2014. Estos documentos evidencian una visión integral, ya que compilan los lineamientos establecidos en el "Concepto para el Desarrollo Socioeconómico a Largo Plazo de la Federación de Rusia para el 2020", la "Estrategia de Seguridad Nacional de Rusia hasta el año 2020", la "Política Exterior de la Federación de Rusia”, y la "Doctrina Marítima de la Federación Rusa hasta 2020”. Además de establecer los intereses 
nacionales, estos documentos incluirían descripciones de lo que Rusia consideraría una amenaza o un peligro militar, y por lo tanto, cómo reaccionar ante cada uno de ellos. Una amenaza militar se caracterizaría "por la posibilidad real del inicio de un conflicto militar entre las partes enfrentadas y por un alto grado de preparación por parte de un determinado Estado (o grupo de Estados) u organizaciones separatistas (terroristas), para utilizar la fuerza militar (violencia armada)" (Ministerio de Defensa de la Federación de Rusia, 2010, p. 2). Del mismo modo, un peligro militar se caracterizaría "por una agregación de factores capaces, en ciertas condiciones, de conducir a la aparición de una amenaza militar" (Ministerio de Defensa de la Federación de Rusia, 2010, p. 2).

Una lectura más cercana de estos documentos de política pública revelaría una mezcla de conservatismo y opiniones progresistas sobre los enfoques rusos de seguridad y defensa, que hasta cierto punto podrían ser contradictorios. Por un lado, la "Estrategia de Seguridad Nacional de Rusia" criticaría el papel de la OTAN como un aparato de seguridad local obsoleto, pero enfatizaría la importancia de la Organización del Tratado de Seguridad Colectiva (OTSC) ${ }^{11}$ como el "principal instrumento interestatal para responder a las amenazas y desafíos regionales de una naturaleza militar-política o militar-estratégica" (Consejo de Seguridad de la Federación Rusa, 2009, p. 3). Del mismo modo, la "Doctrina Militar de 2014" enfatizaría el interés de Rusia en expandir su influencia más allá de sus fronteras, específicamente su presencia en el Ártico, y la importancia de mejorar las relaciones con países emergentes como India, Brasil y China. Finalmente, declararía la adhesión de la Federación de Rusia a las normas y principios del derecho internacional, aunque consideraría legítimo utilizar sus fuerzas militares para garantizar la protección de sus ciudadanos, ubicados fuera de las fronteras de la Federación Rusa. Así mismo, define específicamente la expansión de la OTAN en la región como la principal amenaza periférica de Rusia. Así las cosas, defiende la legitimidad de construir sistemas conjuntos de defensa de misiles por parte de Rusia y las naciones aliadas para defender sus intereses (figura 6).

En el 2015 Moscú lanzaría una nueva Estrategia de Seguridad Nacional (ESN) que contendría las prioridades, los intereses y las amenazas del país en el presente. Con base en este nuevo documento, la gran estrategia de Rusia apuntaría a tres intereses nacionales objetivos prioritarios: 1) crear un nuevo equilibrio de poder más favorable en el sistema internacional; 2) ampliar el acceso a nuevos mercados para la financiación y las exportaciones; y 3) ejercer una influencia más activa en 


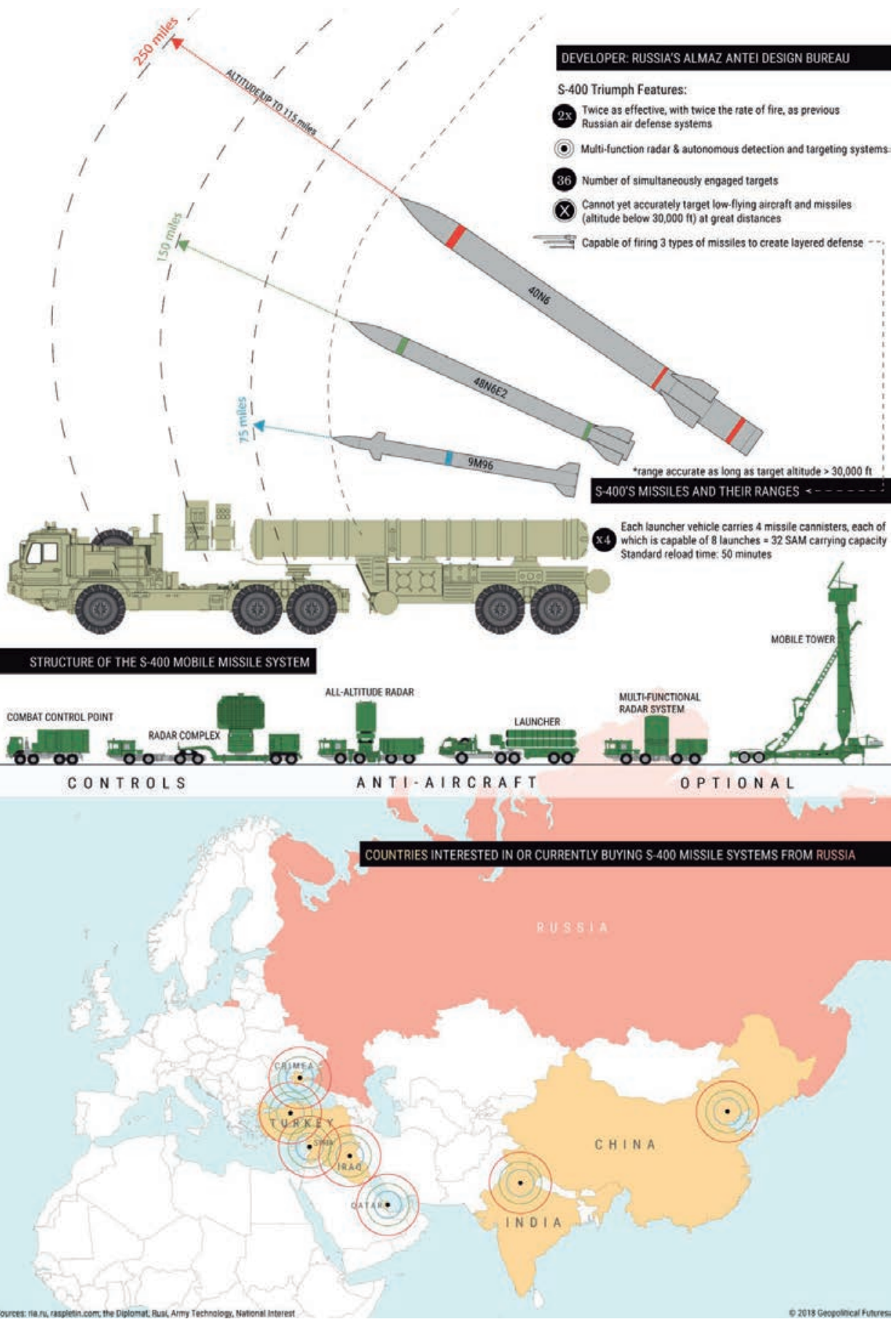

Figura 6. Sistema de Defensa Aérea Avanzada S-400 Triunfo de Rusia.

Fuente: Geopolitical Futures (2018). 
el escenario pos-soviético. Los intereses nacionales objetivos rusos contemplados en la ESN del 2015 guardarían también una estrecha relación con sus imperativos geopolíticos. ${ }^{12}$

Con relación al primer interés nacional objetivo (crear un nuevo equilibrio de poder en el sistema internacional), según el documento de la ESN del 2015, el Estado ruso no tendría una clara aspiración de convertirse en una gran potencia. Sin embargo, Rusia buscaría reconfigurar el actual sistema internacional, que, según su criterio, tendría una marcada orientación occidental. El objetivo de Rusia sería ver a otros actores poderosos respetar los intereses nacionales del Estado ruso, en lugar de asumir los intereses nacionales rusos como contraproducentes al orden mundial. Con este fin, la ESN del 2015 se referiría a la creación y el apoyo de un orden internacional "policéntrico", que haría que el Estado ruso fuera un socio en igualdad de condiciones que los Estados Unidos, la Unión Europea y China. En consecuencia, disminuir el alcance internacional y el impacto de las instituciones occidentales sería indispensable para la creación de este mundo "policéntrico". Esto significaría ejercer un poder astuto ${ }^{13}$ que permita que el orden internacional liberal salga de su centro de gravedad, ya que Rusia se vería ampliamente beneficiado de unas instituciones políticas, de seguridad y económicas occidentales si operase en la incertidumbre.

En cuanto al segundo interés nacional objetivo (abrir mercados y eliminar las sanciones económicas), la gran estrategia de Rusia estaría comprometida con la creación de flujos de efectivo al tesoro estatal, con el fin de acceder a los mercados de exportación de sistemas de armas, petróleo y gas. Con base en lo anterior, un objetivo a corto plazo sería reducir o eliminar las sanciones económicas impuestas al Estado ruso, a las principales compañías financieras rusas y a los funcionarios rusos de alto rango, luego de la anexión de Crimea en el 2014. Las sanciones, combinadas con los bajos precios del petróleo y el gas, supusieron un golpe para las finanzas del Estado, así como para muchas empresas exportadoras dentro de Rusia. Mientras se mantengan estas sanciones, se obstaculizarían los esfuerzos para ampliar los mercados para las exportaciones rusas de gas, petróleo y armas.

Respecto al tercer interés nacional objetivo (ejercer una influencia más activa en el escenario pos-soviético), sería una prioridad del Estado ruso volver a ejercer influjo y proyectar poder en su esfera inmediata de influencia (figura 7), lo que constituiría, a su vez, su principal perímetro de seguridad. Para tales efectos, el

12 Ver capítulo IV.

13 Ver capítulo IV. 
Estado ruso buscaría moldear las políticas exteriores de los Estados vecinos e influir decididamente en sus coaliciones de gobierno. Además, una política rusa anunciada por Putin en marzo del 2014 (poco después de la anexión de Crimea) pretendería defender a las poblaciones rusas en el extranjero; por ende, Moscú estaría persiguiendo una política de influencia más agresiva en los antiguos Estados soviéticos, y la promesa de "protecciones" de las poblaciones rusas en el extranjero señalaría a una Rusia resurgente, lo que generaría en el escenario postsoviético, un círculo de protectorados rusos.

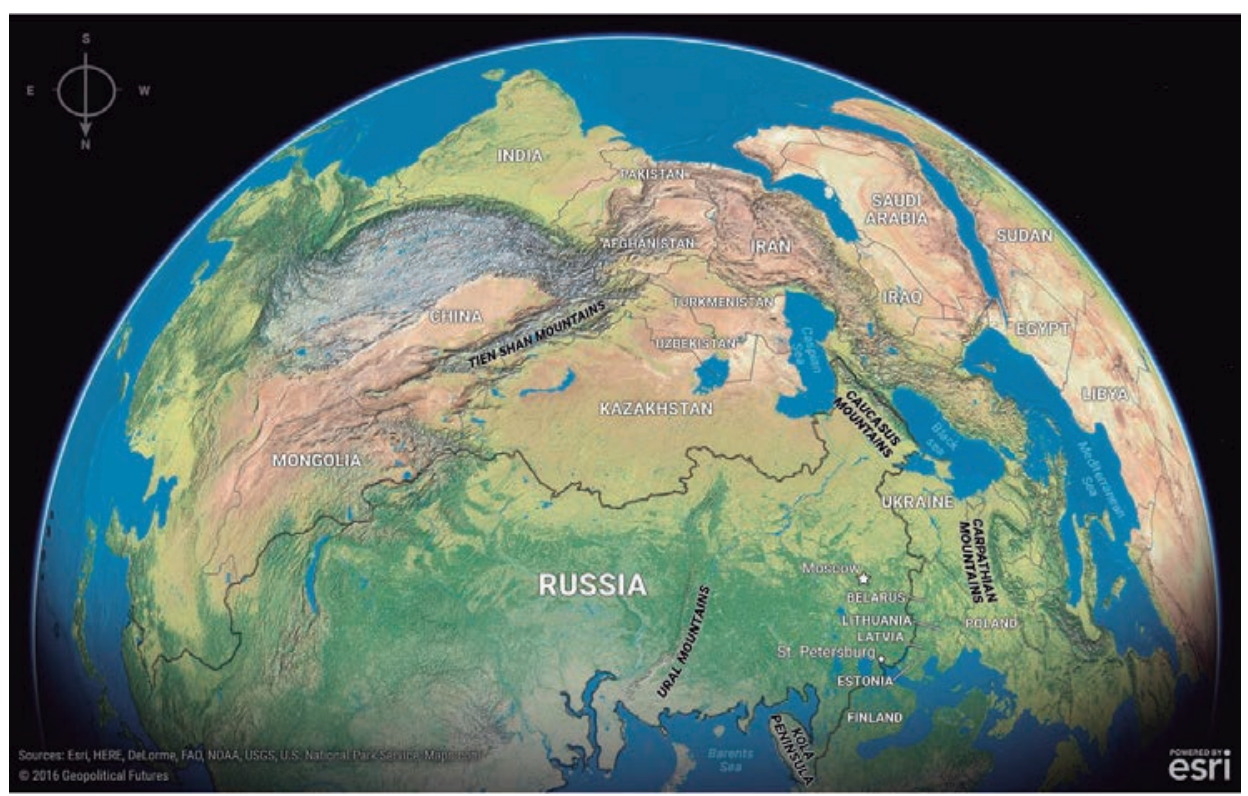

Figura 7. Perspectiva geopolítica de la Federación Rusa. Fuente: Geopolitical Futures (2018).

\subsection{Cultura y pensamiento estratégico en Rusia}

La construcción de la cultura y el pensamiento estratégico en Rusia ha sido un proceso complejo. Durante el tiempo de la URss, el Politburó (principal autoridad política) y su secretario general se enfrentaron a un reto doble. Por una parte, para asegurar sus intereses nacionales debían demostrar el control de la seguridad y defensa en todo el territorio, al tiempo que enmendaban las múltiples debilidades de un intrincado sistema político que, además de congregar a quince naciones con diversas identidades, lenguas y tradiciones, sufría grandes dificultades para mantener un progreso económico equiparable al de los países occidentales. Por otra parte, debían proyectar las bondades del ideal soviético fuera de su territorio, general- 
mente en Estados con inestabilidad política, social o económica, para consolidar un gran bloque a nivel internacional que hiciera frente al avance del sistema capitalista y sus principales defensores.

Así las cosas, uno de los componentes clave para la fundamentación de este pensamiento estratégico, que iría consolidando una cultura estratégica nacional, fue el conjunto de las Fuerzas Militares. Estas deberían ser modernas y eficientes para demostrar el gran poder soviético y responder a las amenazas y desafíos del mundo contemporáneo. Desde el colapso de la Unión Soviética, las Fuerzas Militares rusas habrían experimentado varios intentos de modernización para soportar la visión estratégica nacional. La nueva comprensión de Moscú con respecto a las amenazas y desafíos mundiales del siglo xxi, así como la reducción de la limitación de las ambiciones globales de la era soviética, ha motivado una constante modernización de las Fuerzas Militares, así como una actualización de la seguridad nacional y la doctrina militar (Makarychev y Sergunin, 2013). No obstante, la renovación de un enorme pie de fuerza militar capaz de operar uno de los inventarios de armas e infraestructura militar más extensos del mundo y con profundas tradiciones soviéticas, ha demostrado ser una tarea difícil.

El último líder soviético, Mikhail S. Gorbachev, estableció los primeros planes de transformación para el Ejército soviético (estimada en 1986 en aproximadamente 4.9 millones de hombres y mujeres activos), que fueron heredados por la Federación Rusa (Nichol, 2011). Junto con sus políticas de perestroika (reestructuración) y glasnost (apertura), Gorbachov entendió la falta de alistamiento del Ejército soviético para el escenario que se avecinaba luego de la Guerra Fría, por tanto, importantes recursos destinados originalmente a las Fuerzas Militares se trasladaron a programas de desarrollo y bienestar social, lo que privó a los militares de su precedencia histórica en este asunto (Herspring, 2008a). Además, las acusaciones mutuas entre Gorbachov y los militares por el uso desproporcionado de la fuerza en Tbilisi, Bakú y Vilnius, entre 1989-1991, socavó la opinión pública y la confianza común en ambos bandos (Brown, 1996, p. 264; Barylski, 1998, p. 61; Karavayev, 2012), lo que hizo evidente la necesidad de una reforma militar. Sin embargo, a pesar de diversos intentos de Gorbachov, el único cambio logrado fue una reducción en el personal de las fuerzas armadas, de cinco a cuatro millones (Thornton, 2011), lo que debilitó a las Fuerzas Militares e implicó una pérdida relativa de poder frente al sistema internacional.

El primer presidente de la Federación de Rusia, Boris N. Yeltsin, retomó los proyectos de reforma militar de Gorbachov; sin embargo, centraría sus objetivos en medidas de tinte populista que aumentarían la eficiencia de los militares mediante 
la reducción de presupuesto, para agradar a sus electores y, de paso, garantizar que los militares no actuaran en contra del Gobierno (Herspring, 2006). En consecuencia, los principales esfuerzos de Yeltsin se limitaron a la reducción de la enorme fuerza militar creada durante el período de la URSs, esto incluyó la terminación del sistema de conscripción (servicio militar obligatorio), mediante el fomento de soldados profesionales (kontraktniky). Pero no prestaría atención a la modernización del armamento, del entrenamiento o de los sistemas de mando y control para las tropas.

Desde la era soviética, el servicio militar obligatorio y el sistema de movilización de reservas habían significado un gasto permanente y enorme de recursos. Para contrarrestar esto, la conscripción proporcionaría a las Fuerzas Militares un flujo de personal continuo, y en parte gratuito, ya que no era necesario el pago de salarios; pero al mismo tiempo, privaría a la economía de una mano de obra joven y de mentes inteligentes, especialmente necesarias durante las primeras etapas de la Federación Rusa. Por otra parte, el sistema de movilización para las reservas era una estructura compleja de unidades básicas, conformadas únicamente por oficiales y suboficiales, responsables de mantener las instalaciones y el armamento almacenado en funcionamiento, y para organizar y equipar al personal llamado a filas.

Este sistema drenaba recursos significativos de forma permanente y contribuía poco a la seguridad y defensa de Rusia (Thornton, 2011). Por lo tanto, la justificación de la política de Yeltsin sería simple: la eliminación del reclutamiento eliminaría la necesidad de un sistema de movilización, liberaría fondos y promovería una fuerza militar más pequeńa y efectiva al estar conformada por soldados profesionales. Estas medidas populares promovieron la estabilidad política y la consecución de los intereses nacionales. Incluso a pesar de la lógica de esta reforma, se generaría una gran oposición nacional, principalmente dentro de los altos funcionarios militares y civiles del Gobierno, ya que, en parte, afectaba la creación y el desarrollo de la cultura estratégica en todos los ciudadanos rusos. Según Weitz (2010), estas preocupaciones incluían: 1) el deber natural de cada ciudadano de defender a la patria contra sus agresores y, por lo tanto, la necesidad de estar preparado para hacerlo de manera apropiada; 2) la idea del servicio militar como servicio social que permitiría a los ciudadanos demostrar su gratitud y lealtad a la patria, así como comprender sus necesidades e intereses nacionales; y 3) la importancia de la tarea social de los militares en la construcción de un sentido nacional común de respeto y orgullo por Rusia, a pesar de las diversas raíces étnicas, religiosas o sociales.

La reforma de Yeltsin comenzaría en 1992, con el objetivo de simplificar la organización impuesta desde la era soviética del Ejército (tipo división), para 
pasar a una estructura más flexible (tipo brigada), con el fin de garantizar el alistamiento para el combate en las tropas. Además, un nuevo documento estratégico militar publicado en noviembre de 1993 (Doctrina Militar de la Federación Rusa) respaldaba los planes de modernización, ya que se constituía en un giro hacia una política de seguridad rusa de posicionamiento global más enérgico, diferente del tono defensivo y pacífico de la última doctrina soviética (Blank, 2011a). El objetivo era permitir un mejor entendimiento de los intereses nacionales y de la visión estratégica de la Federación de Rusia, con el fin de simplificar la cadena de mando entre las unidades y reducir el tiempo de respuesta a las órdenes, lo que significaba ahorros financieros para renovar y mantener el inventario de armas. Sin embargo, a pesar de la implementación oficial de la reforma, se obtuvieron resultados disímiles e incluso contradictorios, ya que muchas brigadas nuevas mantendrían el estado de las divisiones, y varias unidades de las divisiones disueltas se reunirían bajo nuevas unidades que, en última instancia, se terminarían convirtiendo en divisiones. Además, la falta de orientación política y unas relaciones civiles-militares adecuadas, privaron a los militares de una idea integral de qué tipo de reformas deberían implementarse para cumplir su función dentro del Estado (Herspring, 2008a).

La Primera Guerra de Chechenia, entre 1994 y 1996, demostraría cómo a pesar del logro publicitado de la reforma a los militares y de la consolidación de un pensamiento estratégico, el desorden en la toma de decisiones había disminuido la preparación para el combate y la capacidad de las tropas rusas. Los terribles resultados de la guerra, incluidos los ataques infligidos a las tropas rusas por los separatistas chechenos, mostrarían el verdadero estado de los militares. Por ello, en 1997, se diseñó un nuevo plan para resolver errores pasados y proporcionar un marco para la innovación. La persona responsable de este nuevo intento fue el mariscal Igor D. Sergeyev, ministro de Defensa, designado por el presidente Yeltsin en mayo de 1997. Como sugiere Parchomenko (1999), el mariscal Sergeyev emprendió las acciones necesarias para que la reforma militar fuera una realidad y, por lo tanto, las modificaciones estructurales más necesarias se alcanzaran en un periodo de dos años: 1) hubo una reducción de las fuerzas del Ministerio de Defensa de casi 1.8 millones en 1997 y de alrededor de 1.2 millones en 1999; 2) se redujeron los distritos militares de la era soviética (se pasó de ocho a seis), 3) se otorgó el control territorial de las tropas y activos existentes en la jurisdicción; y 4) se creó una nueva Fuerza (las Tropas Estratégicas de Misiles), formadas por las antiguas Fuerzas Espaciales Militares, las Fuerzas Estratégicas de Cohetes y las Fuerzas de Misiles y Defensa Espacial. 
El mariscal Sergeyev centró los objetivos de la reforma de 1997 en favorecer al brazo estratégico de fuerzas de cohetes en el que sirvió durante su carrera. Por lo tanto, se utilizaría la teoría de la "optimización bajo un escudo nuclear" (Parchomenko, 1999, p. 100), lo que implicaría recurrir a la disuasión nuclear en lugar de la preparación para el combate real de las tropas y unidades. Como argumenta Orr (2003),

Sergeyev convenció a Yeltsin de que la reforma militar podría lograrse recurriendo a las armas nucleares para disuadir no solo una guerra mundial sino también una gama de amenazas menores. Se necesitarían fuerzas terrestres [del Ejército] para operaciones de mantenimiento de la paz y conflictos menores, pero de lo contrario se podrían hacer economías significativas. (p. 6)

En consecuencia, una gran parte del presupuesto se asignó para misiles balísticos intercontinentales terrestres (Ісвм) SS-27 Topol-M, con el objetivo de reforzar el escudo nuclear de Rusia y de mantener inventarios nucleares mientras que el entrenamiento, material, personal e instalaciones para otras Fuerzas (Ejército, Marina, Fuerza Aérea) recibiría una mínima financiación (Orr, 1998). Además, se tomaron decisiones controvertidas para disminuir los poderes de otros servicios, en particular los del Ejército (el servicio más grande y tal vez más influyente), que sufrirían la disolución de su sede central en 1997.

En 1999, el estallido de la Segunda Guerra Chechena demostraría que las estrategias de Moscú para la modernización militar y la fundamentación de la cultura estratégica eran erróneas. El uso de armas nucleares no fue posible y el Ejército carecía de organización, entrenamiento, material, personal y liderazgo adecuados para manejar la situación de manera eficaz. Los militares tenían poca preparación para el combate y poca capacidad y experiencia en operaciones conjuntas; en consecuencia, la falta de un sistema de comando y control eficiente, así como la ausencia de tecnología e inteligencia, desencadenaron campañas de bombardeo y ataques de tierra que afectaron a sus propias tropas y a la población civil, violaron los derechos humanos y contribuyeron a empeorar la imagen de los militares y a que el entendimiento de la gran estrategia nacional se dificultara (Pain, julio-agosto, 2000; Orr, 2000). La acción del movimiento separatista checheno, clasificado por Moscú como un grupo de simples terroristas y fundamentalistas (Russell, 2005), pero capaz de derribar un número significativo de aviones e infligir varios ataques mortales contra las tropas rusas, reorientó la discusión sobre la preparación de los militares para defender a la patria de las agresiones internas y externas. En consecuencia, se requería una nueva estrategia para renovar el Ejército y detener el número de muertos, estimados en 160.000 combatientes y civiles asesinados en ambas guerras de Chechenia (The New York Times, 2005). 
Cuando Vladimir V. Putin se convirtió en presidente de la Federación de Rusia, en mayo del 2000, apareció una nueva esperanza para la fundamentación de la cultura estratégica. Los antecedentes de Putin como Teniente Coronel de la KGB (reemplazada ahora por el FSB), así como una fuerte agenda nacionalista, proporcionarían una sensación de seguridad y compañerismo entre ciudadanos, políticos y militares. Putin entendió que el concepto de movilización, heredado como una preparación continua para una gran guerra convencional, estaba desviando activos valiosos, mientras que las nuevas amenazas y desafíos, como el terrorismo y la proliferación de armas de destrucción masiva, no estaban teniendo una respuesta adecuada. En efecto, ninguna de las amenazas de un mundo globalizado significaría una acumulación previa de tensiones que permitiría convocar, entrenar y movilizar reservistas. Así mismo, la falta de capacidades de despliegue rápido y de alistamiento para el combate (propias del sistema de movilización), no le proporcionarían a Rusia posibilidades de proyección de poder en una región con interés geopolítico, especialmente en el espacio postsoviético. Por ejemplo, la URSS no mostraría una fuerte capacidad de realizar el tipo de operaciones exitosas como los británicos en las Islas Malvinas, o los Estados Unidos en Panamá o Granada (Thornton, 2011), ni la Federación Rusa tendría la capacidad técnica suficiente para hacer frente al hundimiento del submarino Kursk, en el 2000, durante un importante ejercicio naval en el mar de Barents.

El presidente Putin sabía que, independientemente del aumento de presupuesto para las Fuerzas Militares, era necesario fortalecer el pensamiento estratégico a través de una formulación moderna de la política pública en seguridad y defensa, que reuniera a los campos político y militar alrededor de los intereses nacionales y la realidad del sistema internacional. Por lo tanto, decidió nombrar a un antiguo Coronel General del FsB, Sergei B. Ivanov, como ministro de Defensa. El nombramiento de Ivanov, en marzo del 2001, sería visto como una decisión política que significaba una consolidación del poder de Putin para hacer al Ministerio de Defensa ruso uno más parecido a sus homólogos occidentales, donde los ministros de defensa son civiles y las decisiones hacen parte de la gran estrategia nacional (Vendil, 2008; Galeotti, 2013). Ivanov no era ni civil ni, técnicamente hablando, militar; era una figura con un fondo "mezclado", con la experiencia suficiente para llevar a cabo una reforma militar y la implementación de una cultura estratégica. En octubre del 2003, con la publicación de un documento de política pública denominado "Tareas Urgentes para el Desarrollo de las Fuerzas Armadas de la Federación de Rusia”, el presidente Putin y el Ministro de Defensa Ivanov lanzaron una nueva reforma militar. Este documento oficializaría el plan de reforma a largo plazo elab- 
orado en abril del 2003, destinado a crear una "imagen fundamentalmente nueva de las Fuerzas Armadas” (Ministerio de Defensa de la Federación de Rusia, 2003, p. 1), al convertir al Ejército ruso en un fuerza capaz de manejar una amplia variedad de misiones, incluidos desafíos de seguridad y defensa, lucha contra el terrorismo, operaciones de mantenimiento de la paz y gestión de crisis.

Esta reforma tenía similitudes con otras del pasado, en especial con respecto a algunos de sus objetivos; por ejemplo, reducción de unidades, mejora de la preparación para el combate y reducción del servicio militar obligatorio a favor de soldados profesionales (Liaropoulos, 2008). Sin embargo, también incorporaría nuevas ideas, como la mejora de la gestión financiera, la supervisión política del gasto, los cambios en el sistema educativo militar y la posibilidad de que las mujeres desempeñasen funciones de combate dentro del Ejército. Además, el Jefe del Estado Mayor estaría bajo la égida del Ministerio de Defensa, las cuestiones operativas se trasladarían para que se convirtieran en responsabilidad de este, y no del Estado Mayor, y se otorgaría la oportunidad a los ciudadanos de la Comunidad de Estados Independientes (CIs) para servir en el Ejército, a cambio de obtener la ciudadanía rusa (Herspring, 2005).

Quizás uno de los componentes más importantes de esta reforma sería la aparición de la llamada "doctrina Ivanov", que redefinió la amenaza planteada por la OTAN y señaló nuevas amenazas y desafíos, como el terrorismo y los conflictos de menor escala (Bouldin, 2004). Igualmente, proyectaría el entendimiento de Rusia en la comunidad internacional como una gran potencia con capacidades de poder de alcance global. El mandato del ministro Ivanov duró casi siete años y finalizó en 2007, cuando fue nombrado viceprimer ministro de la Federación de Rusia. Para algunos autores (Sololev y Khodarenok citados por Vendil, 2008; The Moscow Times, 2011; Jensen, 2011), Ivanov fue expulsado debido a la falta de progreso en la reforma y el fracaso del programa de soldados profesionales. Sin embargo, para otros (Herspring, 2008b; Vendil, 2008; Galeotti, 2013), Ivanov fue promovido porque había completado la tarea para la que había sido designado. Ivanov incrementó el presupuesto de defensa, aumentó los salarios, disminuyó el servicio militar obligatorio de 24 meses a 18 meses, en el 2006, y luego a doce meses, en el 2008 (Kamenev, 2009), y preparó al Ejército para el cambio a un ministro de defensa civil, sin vínculos con las fuerzas armadas.

Su reemplazo sería Anatoly E. Serdyukov, jefe del Servicio Federal de Impuestos de Rusia, un civil sin grandes aspiraciones políticas, pero con "experiencia de lidiar con burocracias y olfato para las prácticas corruptas en las que se involucraron muchos altos funcionarios" (Thornton, 2011, p. 14), y capaz de defender 
la reforma de la oposición. Entonces, Serdyukov sería el encargado de iniciar, en el 2008, la más grande reforma de las Fuerzas Militares rusas de los últimos tiempos. Esta reforma, planeada para desarrollarse hasta el año 2020, apuntaría a convertir a las Fuerzas Militares rusas en una fuerza "multimedio" moderna, preparada para afrontar los desafíos globales del siglo Xxi. Además, proyectaría una transformación estructural para acercar a las Fuerzas Militares a los estándares internacionales (al reducir la estructura de la fuerza, maximizar su preparación para el combate), reequiparlas con dispositivos modernos, mejorar la doctrina militar y los programas de instrucción y resolver los problemas de salarios y bienestar (Barabanov et al., 2012; Fernández, 2015). Los resultados de esta reforma aún se encontrarían en evolución y, aunque para ciertos académicos (Vendil, 2008, 2009; De Hass, 2011) esta no ha alcanzado los objetivos propuestos, para otros (Trenin, 2016; Persson, 2016), la reforma ha logrado mejorar sustancialmente la capacidad militar rusa, así como la proyección de su cultura estratégica.

\section{La gran estrategia de los Estados Unidos}

Se ha considerado la administración Truman como la "edad de oro" de la gran estrategia estadounidense, un periodo en el cual se establecerían políticas duraderas para contener el poder soviético y estabilizar el orden mundial. En efecto, a medida que se desarrollaba la Guerra Fría, el presidente Truman y sus asesores comprendieron que la contención representaba un medio deseable entre el apaciguamiento y la guerra, y que contener el poder soviético significaría mantener un equilibrio geopolítico favorable al asegurar y rehabilitar las regiones industriales clave de Europa occidental y el noreste de Asia. La administración norteamericana pondría estas ideas en el centro de su gran estrategia, convirtiéndolas gradualmente en políticas específicas: el Plan Marshall y la Organización del Tratado del Atlántico Norte (OTAN), la reconstrucción económica de Japón y Alemania Occidental, el fortalecimiento de la fuerza militar occidental durante la Guerra de Corea, entre otras (Leffler, 1992).

Según Offner (2002), cuando terminó el periodo del gobierno de Truman, en 1953, la gran estrategia implementada había logrado estabilizar al mundo occidental y sentado las bases para la proyección de poder e influencia de los Estados Unidos en el sistema internacional en los años por venir. La contención ${ }^{14}$ no sería una estrategia que tomó forma en un solo instante; por el contrario, fue desarrollada,

14 Ver capítulo Iv. 
refinada y ajustada en medio de un flujo de eventos constantes; aunque los objetivos básicos y las prioridades geográficas de la administración Truman se mantendrían relativamente constantes a partir de 1948, sus tácticas evolucionaron considerablemente a medida que avanzaba el tiempo. Y aunque el equipo de Truman tendría éxito al combinar la flexibilidad táctica con la visión estratégica, la evolución de la estrategia de contención ocasionaría una serie de dilemas para los Estados Unidos, como, por ejemplo, cuál debía ser el nivel apropiado de gasto militar, cuál debía ser el alcance adecuado de los compromisos internacionales de los Estados Unidos, o cuál la relación entre la retórica y la política, entre otros (Leffler, 1992). Al final, la era Truman daría testimonio no solo de las posibilidades de la gran estrategia, sino también de la complejidad y los límites inherentes a ella.

El gran problema estratégico de la Guerra Fría surgiría directamente de las guerras que le precedieron. La Segunda Guerra Mundial transformaría la posición geopolítica de Estados Unidos, que emergería de ese conflicto con la mitad de la capacidad productiva del mundo y una economía aproximadamente cinco veces más grande que la de sus competidores más cercanos. Además, Estados Unidos representaría casi las tres cuartas partes del gasto militar mundial en 1945, con capacidades nucleares, una fuerza aérea con alcance global y una armada que superaba a todos sus pares combinados (Herring, 2008). No obstante, el ataque a Pearl Harbor, en 1941, había demostrado que los enemigos podían cruzar los océanos para atacar a los Estados Unidos en su propio territorio, por otra parte, los avances en el poder aéreo y la tecnología de misiles aumentaron la posibilidad de ataques aún más devastadores en el futuro. Asimismo, toda la experiencia adquirida durante las décadas de los ańos treinta y los cuarenta parecía demostrar que a los regímenes autoritarios debían enfrentárseles antes de que fuera demasiado tarde, y que la paz y la estabilidad económica mundial estaban intrínsecamente relacionadas.

No sería suficiente, entonces, salvaguardar solamente al hemisferio occidental; con el inicio de la Guerra Fría los Estados Unidos tendrían que definir su seguridad en términos globales. Durante y después de la Segunda Guerra Mundial, las administraciones de Roosevelt y Truman trabajarían para crear un orden económico liberal que pudiera evitar otro traspié que condujese a la depresión económica y la guerra, además, se enfocaron en la creación de las Naciones Unidas, organización que podría usarse para enfrentar a potenciales agresores. Desde un aspecto unilateral, los planificadores militares estadounidenses señalaron la necesidad de un acceso seguro a materias primas y recursos vitales, así como la urgencia de la ampliación de una "frontera estratégica" compuesta por bases militares, desde las cuales las fuerzas estadounidenses pudieran proyectar poder e interceptar enemigos 
lejos de su propio territorio (Ikenberry, 2001). Sobre todo, se tenía consciencia de la necesidad de evitar que cualquier país hostil a los Estados Unidos dominase el heartland teorizado por Mackinder, esa vasta área euroasiática que contenía inmensas capacidades económicas e industriales.

Esta sería una concepción expansiva de los intereses estadounidenses de la posguerra, sin embargo, la Segunda Guerra Mundial ocasionó una serie de dificultades que ponían en peligro esta visión. En efecto, dicha guerra dejó en Europa y Asia amplias áreas devastadas en lo militar, lo económico y lo político, esto fracturó el equilibrio internacional del poder y elevó el grado de agitación y revolución en diversos Estados, como eventualmente sucedería en China. Igualmente, la Segunda Guerra Mundial llevó a los británicos y franceses al límite de la bancarrota, lo que los incapacitó para desempeñar su papel tradicional como estabilizadores globales, socavó el orden colonial en las regiones en desarrollo y provocó oleadas de nacionalismo y radicalismo en Asia, África y Medio Oriente.

En consecuencia, la gran estrategia estadounidense a partir de 1947 sería moldeada mediante una combinación acertada de planificación e improvisación. Con las crisis que se avecinaban en casi todas partes, las prioridades y la planificación serían esenciales, para ello Truman nombraría al General Marshall como su nuevo Secretario de Estado, a quien otorgó una amplia libertad en la conducción de la política exterior. Marshall conformó rápidamente el denominado Personal de Planificación de Políticas (PPS), encargado de desarrollar programas a largo plazo para el logro de los objetivos de la política exterior de los Estados Unidos. Nombró a George F. Kennan (1967) como su director, quien consideraba que para que la diplomacia de los Estados Unidos tuviese éxito, en Washington se necesitaría "un patrón de gran estrategia no menos concreta y consistente que la que rige nuestras acciones durante la guerra" (p. 327). El mismo imperativo se sentía en todo el poder ejecutivo; para abril de 1947 los Jefes de Estado Mayor Conjunto de los Estados Unidos realizarían un estudio importante para determinar las prioridades en la asignación de asistencia militar y recursos en general (Paterson, 1992), y con la aprobación de la Ley de Seguridad Nacional, se crearía la Agencia Central de Inteligencia (CIA) y el Consejo de Seguridad Nacional, así como a el Establecimiento Militar Nacional unificado (que más tarde sería el Departamento de Defensa).

Si a la administración Truman se le atribuye la construcción del orden mundial durante el periodo de la Guerra Fría, Richard Nixon y Henry Kissinger tendrían la desgracia de gobernar un orden mundial en proceso de deconstrucción. En efecto, la estrategia de contención estaría en crisis hacia finales de los años sesenta; la guerra de Vietnam había expuesto los límites del poder de Estados Unidos y 
la profundidad de sus divisiones sociopolíticas en el ámbito doméstico, mientras que el sistema internacional en su conjunto se estaba alejando de la atmósfera de posguerra de la hegemonía estadounidense (Rodman, 1994). Por lo tanto, Estados Unidos necesitaría políticas verdaderamente innovadoras que permitieran preservar la estabilidad mundial en una era de relativo declive norteamericano.

Kissinger creía que los grandes líderes no solo tenían que reaccionar a los desafíos que enfrentaban, sino que debían superar estos juicios e imponer su propio propósito a los acontecimientos; esta sería la esencia de la gran estrategia durante las administraciones de Nixon y Ford: no solo hacer coincidir los medios con los fines, sino librar una lucha más profunda para "dar forma a las corrientes de nuestro tiempo a la luz de nuestros valores” (Kissinger, 1961, p. 8). Durante su tiempo en el poder, ${ }^{15}$ Nixon y Kissinger siguieron una muy ambiciosa gran estrategia que pretendía aumentar la flexibilidad estratégica de los Estados Unidos para el mantenimiento de la hegemonía global, al disminuir las cargas económicas, políticas y militares que implicaba el esfuerzo de contención hacia la Unión Soviética; creían que esta gran estrategia podría permitirle a los Estados Unidos superar su crisis de relativo declive y dar forma a los contornos de un orden mundial más estable. Para ello se impulsó la apertura a China, la conclusión del Tratado sobre Misiles Anti-Balísticos y otras negociaciones con Moscú, el manejo de la Guerra de Yom Kippur, e incluso la devolución de la responsabilidad de la seguridad a los aliados locales en el Tercer Mundo, entre otras iniciativas. Sin embargo, según Garthoff (1994), el virtuosismo geopolítico al que aspiraba la administración Nixon no pudo traducir los primeros triunfos de la política de "détente" (distensión) y la diplomacia triangular en una estructura duradera de estabilidad en el periodo de Guerra Fría; tampoco lograría liberar a Estados Unidos de la guerra de Vietnam, ni facultarlo a enfrentar las diversas crisis del Tercer Mundo, o temas emergentes como los derechos humanos y las crisis del petróleo (Kissinger, 2003). En consecuencia, hacia mediados de la década de los setenta, la gran estrategia de Nixon-Kissinger comenzaría a entrar en crisis.

Uno de los principales críticos de las estrategias implementadas por Nixon y Kissinger sería el exgobernador de California Ronald Reagan, quien emergería como una figura central del Partido Republicano luego de la renuncia de Nixon en 1974. Durante las primarias republicanas de 1976, Reagan había atacado la política de distensión como una abdicación de la herencia moral de Estados Unidos

15 Nixon como presidente, desde 1969 hasta 1974, y Kissinger como Asesor de Seguridad Nacional, de 1969 a 1975, y Secretario de Estado, de 1973 a 1977, en las administraciones Nixon y Ford. 
y un enfoque peligrosamente ingenuo de la Guerra Fría, de hecho mantuvo dicha postura incluso después de que Jimmy Carter asumiera la presidencia de los Estados Unidos, en 1977. Reagan advirtió que Estados Unidos se estaba quedando rezagado en la carrera de armamentos estratégica contra los soviéticos y que estos estaban explotando la política de distensión para obtener ventaja en el Tercer Mundo (Matlock, 2004). Asimismo, argumentaría que Estados Unidos podría revertir estas tendencias y recuperar la ventaja geopolítica sobre Moscú, pero solo si desarrollaba una estrategia diplomática de largo alcance para enfrentar a la Unión Soviética.

En términos generales, la gran estrategia de la administración Reagan se basaría en la idea de que la Unión Soviética era mucho más débil de lo que parecía a fines de los años setenta, y que Estados Unidos podía aprovechar esa debilidad para ejercer presión en los ámbitos militar, económico, político e ideológico (Velasco, 2010). Entonces, el objetivo principal de las iniciativas no sería forzar el colapso de la Unión Soviética, sino proporcionar una influencia diplomática que podría usarse para moderar el comportamiento soviético y reducir las tensiones de la Guerra Fría en términos favorables para los Estados Unidos; es decir, la gran estrategia de Reagan estaría destinada a capitalizar las ventajas competitivas de Estados Unidos con respecto a Moscú para revertir la marea de la Guerra Fría.

En este orden de ideas, los elementos clave de esta gran estrategia se agruparían en dos importantes directivas de decisión emitidas en 1982 y 1983. La primera, la NSDD-32, describía el "desarrollo e integración de un conjunto de estrategias incluidos los componentes diplomáticos, informativos, económicos, políticos y militares" (The White House, 1982, box 1), y argumentaba que los objetivos estadounidenses debían ser: 1) fortalecer la influencia de los Estados Unidos en todo el mundo; 2) contener y revertir la expansión del control soviético y la presencia militar en todo el mundo; 3) desalentar el aventurismo soviético y debilitar el sistema de alianza soviético al obligar a la Unión Soviética a soportar la mayor parte de sus deficiencias económicas; y 4) fomentar las tendencias nacionalizadoras y liberalizadoras a largo plazo dentro de la Unión Soviética y los países aliados. Las mismas ideas serían refinadas y reafirmadas por la NSDD-75, en la que se exponía explícitamente los objetivos y etapas esenciales de la política de Reagan (The White House, 1983).

De acuerdo con Matlock (2004), al asumir la presidencia en 1981, Reagan presidiría una mejora verdaderamente asombrosa en las fortunas geopolíticas de Estados Unidos, en un momento histórico en el que parecía que la Guerra Fría la estaban ganando los soviéticos y en el que Estados Unidos y sus aliados estaban a la defensiva. Ocho años después de asumir las riendas del Estado norteameri- 
cano, serían los soviéticos quienes se estarían retirando en prácticamente todos los frentes, lo que llevaría a Ronald Reagan y Mikhail Gorbachev a proclamar el fin de la Guerra Fría. Por ende, los documentos de la Estrategia Nacional de Seguridad estadounidense durante la era Reagan demostrarían que hubo una nueva gran estrategia, basada una visión integral a largo plazo de la política de los Estados Unidos hacia Moscú, en la cual la gran estrategia estaría cimentada en el uso de todas las capacidades del poder nacional estadounidense.

El colapso de la Unión Soviética consolidaría a los Estados Unidos como la única gran potencia y eliminaría la amenaza de seguridad dominante que había concentrado la atención en la política exterior norteamericana durante décadas. No obstante, los funcionarios estadounidenses enfrentarían durante la década de los noventa diversos problemas, que iban desde catástrofes humanitarias y conflictos étnicos, hasta crisis regionales y la proliferación nuclear de Estados como Irán o Corea del Norte. Sin embargo, ninguno de estos desafíos sería tan apremiante como el de la Unión Soviética, pues la rápida expansión de la democracia y la economía del libre mercado crearían la sensación de que el mundo se estaba rehaciendo bajo una visión estadounidense. Como resultado, el sistema internacional adoptaría momentáneamente una naturaleza unipolar, precisamente porque Estados Unidos parecía tan poderoso, que se presentaría una ambivalencia que se hizo evidente en la política exterior estadounidense durante la administración Clinton.

Según Halberstam (2002), Bill Clinton consideró que valía la pena preservar y mejorar la posición dominante de Estados Unidos, razón por la cual terminaría promoviendo varias iniciativas como la expansión de la OTAN y la promoción de la democracia y el libre mercado. Sin embargo, ante la ausencia de cualquier desafío importante a la seguridad nacional de los Estados Unidos (Álvarez et al., 2017a), ya los estadounidenses no estaban ansiosos por gastar muchos recursos económicos y humanos en la defensa de sus intereses en el extranjero; la promoción de la democracia se intentaría principalmente a través de medios diplomáticos y económicos, y después de una desventura operacional en Somalia, la administración Clinton se apoyaría en el uso de misiles de crucero y el poder aéreo cuando se requería el uso de la fuerza militar. Por lo tanto, la administración Clinton adoptaría una actitud ambivalente hacia la idea de la gran estrategia, ya que bajo la perspectiva de Clinton la gran estrategia podría causar más problemas de los que eventualmente podría llegar a resolver (Suri, 2009). De acuerdo con Brands (2008), tales perplejidades molestarían a la comunidad estadounidense en los estudios estratégicos, que a menudo alegaba que la política exterior estadounidense carecía de dirección alguna. 
No sería entonces sino hasta el ataque del 11 de septiembre de 2001 que los Estados Unidos se verían forzados, nuevamente, a diseñar una gran estrategia que se adaptara a los nuevos tiempos. Los ataques al World Trade Center y al Pentágono, llevados a cabo por parte de Al Qaeda, demostrarían que la mera existencia del poder militar estadounidense no garantizaría completamente la seguridad estadounidense, ya que, por el costo de unos 500.000 dólares, 19 hombres armados con bisturís habían tomado casi 3000 vidas y expuesto a Estados Unidos a un grado de destrucción que no se había visto en generaciones, lo que demostraba que actores comparativamente débiles podrían perpetrar niveles catastróficos de violencia. Tras los ataques y con el inicio de las Guerras de Quinta Generación (Álvarez et al., 2017b), la administración de Bush (hijo) lanzó una campaña militar contra Al Qaeda y los talibanes, además, simultáneamente, declaró una "guerra contra el terrorismo" y diseñó una gran estrategia para ese conflicto. En cuestión de meses Bush anunciaría su intención de preservar la hegemonía militar estadounidense mediante el ataque preventivo y de manera unilateral, no solo contra las amenazas existentes, sino también contra aquellos Estados "deshonestos" que buscaban obtener armas de destrucción masiva.

De acuerdo con esos principios, autorizaría la invasión de Afganistán y de Irak (un país que no tenía nada que ver con los sucesos del 11 de septiembre), así como la promoción de la democracia en Medio Oriente, no a través de instrumentos de poder suave como los que se habían utilizado durante la era Clinton, sino mediante el uso de los recursos de poder duro de los Estados Unidos. En consecuencia, y en el espacio de dieciocho meses, los Estados Unidos se habían embarcado en un curso de acción que era impresionante no solo por su alcance, sino también por los recursos requeridos. Pero a pesar de ciertos resultados operacionales favorables en Medio Oriente, la gran estrategia de Bush terminó siendo contraproducente al momento de lidiar con Estados como Irán y Corea del Norte, ya que al incluir estos regímenes en el "eje del mal" y negarse a sostener negociaciones directas en espera de su derrocamiento, quedó demostrado que Estados Unidos prefería el uso de la fuerza (al derrocar al gobierno de Saddam) y se envió la señal inequívoca de que solo las armas nucleares podrían garantizar la seguridad iraní o norcoreana (Halberstam, 2002).

Sin embargo, al dedicar recursos militares de los Estados Unidos a lo que resultaría ser una guerra costosa y agotadora, la administración también perdió la fuerza y la credibilidad coercitiva que eran esenciales para que una política de confrontación tuviera alguna posibilidad de éxito (Feith, 2008); en otras palabras, la política de Bush terminaría privando a los Estados Unidos tanto de la "zanahoria" 
como del "garrote". La gran estrategia de Bush también tendría consecuencias desafortunadas con respecto al desafío de proteger la primacía de los Estados Unidos, ya que si bien la guerra de Irak no causó el crecimiento del poder chino, ni impidió que la administración Bush estableciera relaciones generalmente productivas con Pekín en una amplia gama de temas, tampoco evitaría el ascenso de potenciales competidores de los Estados Unidos por la hegemonía global.

Según Brands (2008), funcionarios clave del Pentágono argumentarían que Estados Unidos necesitaba comenzar a cambiar de enfoque hacia la región asiática para enfrentar la perspectiva de una China emergente, pero Estados Unidos estaba envuelto en una guerra de desgaste en el Medio Oriente. Efectivamente, el equilibrio militar en el Asia estaba cambiando durante el mandato de Bush; por ejemplo, el gasto militar chino aumentaría en un $189 \%$ durante la primera década del siglo xxI (Friedberg, 2011), permitiéndole al Gobierno chino desarrollar sus capacidades de acceso/negación del área, tales como misiles balísticos, capacidades antisatélite, cazas aéreos y submarinos nucleares, que permitirían mantener a raya a las fuerzas de los Estados Unidos en un posible conflicto por Taiwán u otras contingencias regionales. Además, y en línea con estas adquisiciones, el Estado chino también desarrollaba conceptos estratégicos destinados a explotar las vulnerabilidades del vacío de una gran estrategia estadounidense que proyectase las capacidades de poder de los Estados Unidos en el este de Asia, lo que, de hecho, podría ser el principal dilema estratégico en el que se encuentra en la actualidad la administración Trump.

\subsection{Intereses e imperativos geoestratégicos de los Estados Unidos en el siglo XXI}

A finales del 2017 Estados Unidos publicaría una nueva ESN que sostendría que, en un mundo hipercompetitivo, Estados Unidos debería estar preparado para competir en las mejores condiciones, comenzando por su escenario interno. Por lo tanto, la ESN del 2017 contemplaría cuatro intereses nacionales objetivos de los Estados Unidos: 1) proteger el territorio, la soberanía y el "estilo de vida estadounidense”; 2) promover la prosperidad del Estado; 3) preservar la paz a través de la fuerza; y 4) promover la influencia de los Estados Unidos en el mundo. Asimismo, dichos intereses nacionales objetivos guardarían una relación con los siguientes imperativos geopolíticos norteamericanos: 1) dominar el núcleo vital norteamericano (Gran Cuenca del Mississippi); 2) eliminar todas las amenazas terrestres al núcleo vital; 3) controlar las aproximaciones marítimas a los Estados Unidos; 4) controlar los océanos del mundo; y 5) evitar el ascenso de potenciales competidores hegemónicos. 
Con base en el primer interés nacional objetivo contemplado en la ESN del 2017, el de la protección del territorio, la soberanía y el "estilo de vida estadounidense" (que contemplarían los imperativos geopolíticos 1, 2 y 3), la administración Trump consideraría que es fundamentalmente importante el control de las fronteras y de la inmigración de personas a suelo estadounidense, ya que, en su criterio, los flujos ilegales de seres humanos no solo atentarían contra la seguridad económica del país, sino que además serían la principal fuente de criminalidad en los Estados Unidos, como en el caso de las organizaciones delincuenciales mexicanas que operan en suelo norteamericano (figura 8). Asimismo, la ESN del 2017 consideraría importante proteger las infraestructuras críticas y evitar que actores estatales y no estatales foráneos utilicen el ciberespacio para emprender campañas que pongan en riesgo la seguridad nacional de los Estados Unidos.

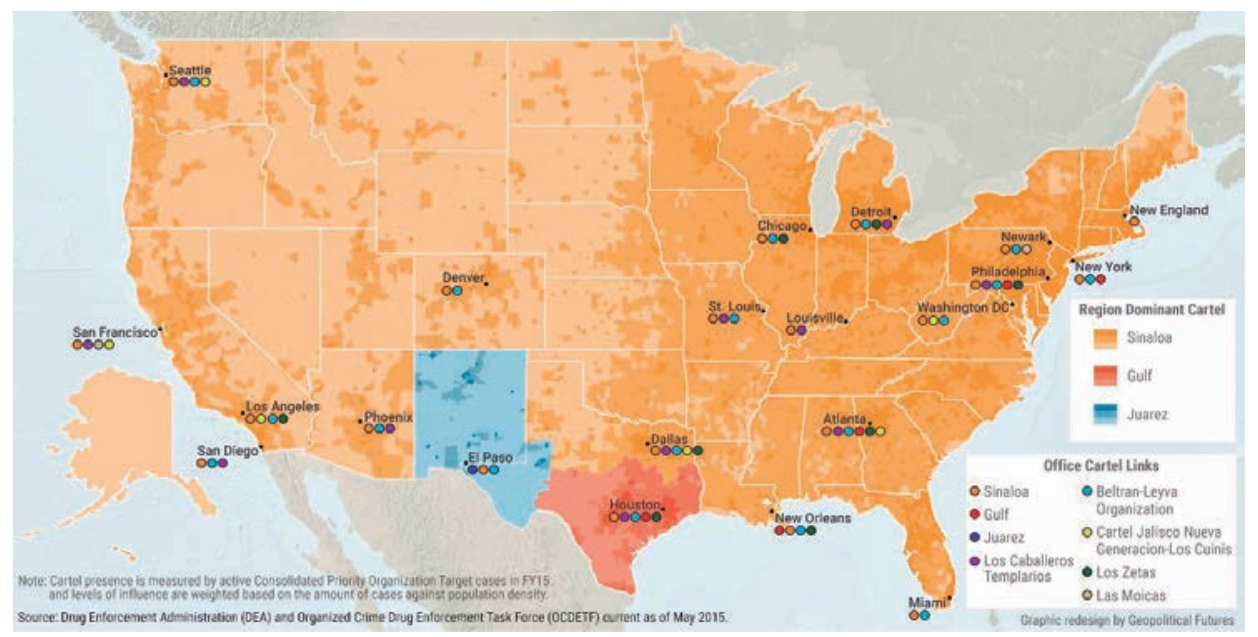

Figura 8. Crimen organizado transnacional mexicano en los Estados Unidos. Fuente: Geopolitical Futures (2018).

El segundo interés nacional objetivo (que guardarían relación con los imperativos geopolíticos 4 y 5), basado en la promoción de la prosperidad del Estado, es un interés nacional ligado a la seguridad económica de los Estados Unidos que buscaría hacerla más competitiva en los mercados internacionales. Por ende, su insistencia en ser firme con China y en renegociar muchos de los acuerdos comerciales bilaterales de los Estados Unidos, reflejaría su deseo de aumentar la competitividad de los Estados Unidos. Las dificultades en la balanza comercial entre los Estados Unidos y China no radicarían tan solo en la aritmética de los aranceles y el comercio, sino en la naturaleza misma de la relación comercial. Si bien el superávit 
comercial de China (375 mil millones de dólares) es ciertamente un problema, no sería el principal, ya que en muchos sentidos reflejaría el poder de los consumidores estadounidenses y la sofisticación de la economía norteamericana. La raíz de la discordia radicaría en que Estados Unidos no tendría las mismas condiciones de igualdad para ofertar sus bienes y servicios de alta gama en el mercado de consumo de mayor crecimiento del mundo. Por lo tanto, si bien la actual guerra comercial entre ambos Estados ha afectado a ciertos sectores de los Estados Unidos, y seguramente habrá costos a largo plazo para la economía norteamericana al perder acceso al gigantesco mercado chino, la economía de los Estados Unidos estaría actualmente en la cima del ciclo económico, lo que le permitiría avanzar en sus demás intereses nacionales objetivos,

La administración Trump consideraría que el orden mundial solo es posible mediante las demostraciones de fuerza (económicas, militares y diplomáticas) y el fortalecimiento de las capacidades militares norteamericanas; en ese sentido, y junto a las sospechas que rodean las ambiciones geopolíticas chinas y rusas, cualquier acción por parte de Washington que debilite a ambos Estados (así sea comercialmente) valdría la pena llevarse a cabo. ${ }^{16}$ Por lo tanto, el principal objetivo de la gran estrategia estadounidense en el presente sería el de contener el surgimiento de China y Rusia, lo que implica para Estados Unidos el uso de todos los instrumentos de su poder nacional para competir con estos rivales estratégicos. Con el retorno de la competencia geopolítica, Estados Unidos tendría la convicción de que solo prevalecerá sobre China y Rusia con sólidos fundamentos internos; para lograrlo, Estados Unidos buscaría asegurar la prosperidad económica, recuperar su liderazgo tecnológico, defender su propiedad intelectual y llevar la propia competencia geopolítica al espacio exterior y al ciberespacio. Al final, la nueva estrategia es una amalgama de la cultura estratégica tradicional de seguridad nacional de los Estados Unidos, en la que la lucha contra el terrorismo y el compromiso con sus aliados ya no sería la máxima prioridad en seguridad y defensa.

16 Todo esto sugeriría que los Estados Unidos y China estarían comenzando a reconfigurar sus respectivas economías; los Estados Unidos estarían dejando de ayudar indirectamente a China y crearían incentivos para que las empresas multinacionales redireccionen las cadenas de suministro de China hacia los Estados Unidos, y China estaría reduciendo su dependencia en el mercado y la tecnología norteamericana. De tal modo que con suficientes socios fuera de los Estados Unidos, y con suficiente dinero para enfrentar el desafío, puede que China realmente tenga éxito en el futuro próximo. 


\section{Conclusiones}

Desde sus orígenes, China y Rusia entraron en el escenario mundial como Estados que buscaban conseguir el respeto internacional e influir en el sistema internacional. Esa conversión, que impuso en la política exterior de ambos países una visión pragmática de las relaciones internacionales, no solo se ha mantenido con el tiempo, sino que además se ha sofisticado y profundizado hasta el día de hoy. Tanto China como Rusia emplearían la globalización para alcanzar metas geopolíticas y harían uso de los instrumentos clásicos de la geopolítica para mejorar sus capacidades de influencia en el proceso de globalización, haciendo uso de sus pesos geopolíticos, económicos y militares para abrir mercados y acumular recursos energéticos, de bienes y servicios, tecnológicos y de capital. Tanto así, que la obsesión por garantizar y defender el interés y la seguridad nacional podría identificarse en abundancia en los comportamientos recientes de la política exterior de ambos Estados, en sus respectivas esferas de influencia. Esta mentalidad en relaciones internacionales parecería corroborar algunas tendencias geopolíticas recientes en Europa Oriental y el Sudeste Asiático, al tiempo que desafía sutilmente la presencia y la influencia de Estados Unidos en otras partes del globo, como América Latina.

No obstante, Estados Unidos ha podido convivir con la contradicción que supondría ser, al mismo tiempo, una potencia conservadora y revolucionaria. La gran estrategia sería un proceso esencialmente optimista, ya que se basaría en la idea de que los Estados podrían llegar a combinar visión y racionalidad con el poder; sostiene que el pensamiento y la cultura estratégica en seguridad y defensa de una sociedad podrían salvar el orden del caos, e imponer su propio significado a los eventos. Por ende, la gran estrategia debería comenzar con la planificación sistemática, el establecimiento de objetivos y prioridades, y el esbozo de un curso de acción realista para alcanzar esos objetivos. Sin embargo, independientemente de qué tan bien se realice esta planificación inicial, la progresión posterior de los eventos inevitablemente requerirá que se revise la hoja de ruta, se reconsideren las suposiciones y se planeen nuevas rutas para alcanzar los intereses nacionales y los imperativos geopolíticos.

Si bien las incertidumbres e imprevistos no son bien recibidos, son inevitables en el sistema internacional; por más que los altos funcionarios del Estado se enfrentan constantemente a escenarios que no esperaban, e incluso preparen los planes de contingencia más meticulosos, no pueden anticiparse a todo lo que podría salir mal. En consecuencia, los líderes necesitarían un conjunto básico de principios y objetivos, pero también evitar casarse estrechamente con un solo curso 
de acción, ya que la prueba real de una gran estrategia, a menudo, radicaría en la eficacia con la que sus autores pueden adaptarse cuando las cosas no proceden de acuerdo con el diseño previsto. Por ende, la gran estrategia no debería ser vista como algo fijo o finito, sino como un proceso continuo e iterativo, que implica enfrentar sorpresas y corregir el rumbo cuando sea necesario, mientras se mantiene presente y en todo momento el objetivo final. Tal parecería ser el caso de Estados Unidos en el presente, a pesar de lo que digan algunos contradictores de la administración Trump.

\section{Referencias}

Álvarez, C., Rosanía, N., Sánchez, D. y Jiménez, G. (2017a). Seguridad y Defensa: Conceptos en Constante Transformación. En C. Álvarez (ed.), Escenarios y Desafios de la Seguridad Multidimensional en Colombia (pp. 29-83). Bogotá: Ediciones Escuela Superior de Guerra.

Álvarez, C., Santafe, G. y Urbano, O. (2017b). Metamorphosis Bellum: ¿¿Mutando a Guerras de Quinta Generación? En C. Álvarez (ed.), Escenarios y Desafos de la Seguridad Multidimensional en Colombia (pp. 145-248). Bogotá: Ediciones Esdegue.

Ardila Castro, C., \& Rodríguez, J. (2018). Visión geoestratégica china y su incidencia sobre Latinoamérica y África. Revista Científica General José María Córdova, 16(23), 1-22. https://doi. org/10.21830/19006586.303

Barabanov, M., Makienko, M. y Pukhov, R. (2012). Military Reform: Toward the New Look of the Russian Army. Moscow: Valdai Discussion Club. Recuperado de http://valdaiclub.com/publication/46540.html

Barylski, R. (1998). The Soldier in Russian Politics 1988-1996. Piscataway, New Jersey: Transaction Publishers.

Bergsten, F., Freeman, C., Lardy, N. y Mitchell, D. (2008). China's Rise: Challenges and Opportunities. Washington: Peterson Institute for International Economics.

Blank, S. (ed.) (2011a). Russian Military Politics and Russia's 2010 Defense Doctrine. Recuperado de http:// www.strategicstudiesinstitute.army.mil/pubs/display.cfm?pubID=1050

Bouldin, M. (2004). The Ivanov Doctrine and Military Reform: Reasserting Stability in Russia. The Journal of Slavic Military Studies, 17(4), pp. 619-641.

Brands, H. (2008). From Berlin to Baghdad: America's Search for Purpose in the Post-Cold War World. Lexington: University Press of Kentucky.

Brown, A. (1996). The Gorbachev Factor. Oxford: Oxford University Press.

CICR (2005). National Economic Security. Beijing: Current Affairs Publishing House.

Consejo de Seguridad de la Federación de Rusia (2009). Russian Federation National Security Strategy through 2020. Recuperado de http://www.isn.ethz.ch/Digital-Library/Publications/Detail/:id=154915

De Hass, M. (2011). Russias Military Reforms. Victory after Twenty Years of Failure? Clingendael Papers. Netherlands Institute of International Relations. Recuperado de http://www.clingendael.nl/sites/ default/files/20111129_clingendaelpaper_mdehaas.pdf 
Dufort, P. (2017). La influencia de la comprensión cambiante del poder sobre la estrategia: un ensayo genealógico. Revista Científica General José María Córdova, 15(19), 29-81. https://doi. org/10.21830/19006586.83

Feith, D. (2008). War and Decision: Inside the Pentagon at the Dawn of the War on Terrorism. New York: Harper Collins.

Fernández-Osorio, A. (2015). Operaciones militares de espectro total: ¿fundamento de la Reforma Militar Rusa de 2008? Revista Científica General José María Córdova, 13(15), 63-86. doi. org/10.21830/19006586.11

Friedberg, A. (2011). A Contest for Supremacy: China, America, and the Struggle for Mastery in Asia. New York: W. W. Norton.

Galeotti, M. (ed.) (2013). The Politics of Security in Modern Russia. Farrnham: Ashgate Publishing, Ltd.

Garthoff, R. (1994). Détente and Confrontation: Soviet-American Relations from Nixon to Reagan. Washington: Brookings Institution Press.

Gill, B. (2007). Rising Star: China's New Security Dilpomacy. Washington: Brookings Institution Press.

Goldstein, A. (2005). Rising to Challenge: China's Grand Strategy and International Security. Stanford: Stanford University Press.

Guo, S. (2013). Chinese Politics and Government: Power, ideology, and Organization. New York: Routledge.

Halberstam, D. (2002). War in a Time of Peace: Bush, Clinton, and the Generals. New York: Simon y Schuster.

Herring, G. (2008). From Colony to Superpower: U. S. Foreign Relations since 1776. New York: Oxford University Press.

Herspring, D. (2005). Vladimir Putin and Military Reform in Russia. European Security, 14(1), pp. 137-155.

Herspring, D. (2006). Undermining Combat Readiness in the Russian Military, 1992-2005. Armed Forces y Society, 32(4), pp. 513-531.

Herspring, D. (2008a). Russian Military Reform and Anatoly Serdyukov. Recuperado de http://web.mit. edu/ssp/seminars/wed_archives08fall/herspring.html

Herspring, D. (2008b). Russian Military Reform and Anatoly Serdyukov. Problems of Post-Communism, 55(6), pp. 20-32.

Ikenberry, G. (2001). After Victory: Institutions, Strategic Restraint, and the Rebuilding of Order after Major Wars. Princeton: Princeton University Press.

Jensen, D. (2011). Sergei Ivanov Returns to Center Stage. Institute of Modern Russia. Recuperado de http://imrussia.org/politics/427-sergei-ivanov-returns-to-center-stage

Kamenev, M. (2009). How to Dodge the Draft in Russia. Time. Recuperado de http://content.time.com/ time/world/article/0,8599,1888238,00.html

Karavayev, A. (2012). Baku, Vilnius, Tbilisi. Vestink Kavkaza. Recuperado de http://vestnikkavkaza.net/ analysis/politics/22339.html

Kennan, G. (1967). Memoirs 1925-1950. Boston: Little, Brown.

Kissinger, H. (1961). The Necessity for Choice: Prospects of American Foreign Policy. New York: Harper y Brothers.

Kissinger, H. (2003). Crisis: The Anatomy of Two Major Foreign Policy Crises. New York: Simon y Schuster. 
Kong, B. (2010). China's International Petroleum Policy. Santa Barbara: Praeger Security International.

Leffler, M. (1992). Preponderance of Power: National Security, the Truman Administration, and the Cold War. Stanford: Stanford University Press.

Liaropoulos, A. (2008). The Russian Defense reform and its limitations. Caucasian Review of International Affairs, 2(1), pp. 42-49.

Li, C. (2010). China's Communist Party State: The Structure and Dynamics of Power. En W. Joseph (ed.), Politics in China: An Introduction (pp. 165-192). Oxford: Oxford University Press.

Lobell, S., Ripsman, N. y Taliaferro, J. (2008). Neoclassical Realism, the State, and Foreign Policy. New York: Cambridge University Press.

Matlock, J. (2004). Reagan and Gorbachev: How the Cold War Ended. New York: Random House.

Medeiros, E. (2007). China’s International Behavior: Activism, Opportunism, and Diversification. Joint Forces Quarterly, (47), pp. 34-41.

Makarychev, A. y Sergunin, A. (2013). Russian military reform: institutional, political and security implications. Defense y Security Analysis, 29(4), pp. 356-364.

Ministerio de Defensa de la Federación de Rusia (2003). Urgent Tasks for the Development of the Armed Forces of the Russian Federation. Recuperado de http://red-stars.org/doctrine.pdf

Nichol, J. (2011). Russian Military Reform and Defense Policy. CRS Report for Congress. Congressional Research Service. Recuperado de http://www.fas.org/sgp/crs/row/R42006.pdf

Offner, A. (2002). Another Such Victory: President Truman and the Cold War. Stanford: Stanford University Press.

Orr, M. (2000). Better or Just not so Bad? An Evaluation of Russian Combat Effectiveness in the Second Chechen War. Recuperado de https://www.google.ru/url?sa=t\&rct=j\&q=\&esrc=s\&source $=$ web $\& \mathrm{~cd}=2 \& \mathrm{cad}=$ rja $\&$ uact $=8 \& \mathrm{ved}=0 \mathrm{CCwQFjAB} \& u r l=$ http $\% 3 \mathrm{~A} \% 2 \mathrm{~F} \% 2 \mathrm{Fda}$. mod . uk\%2FCSRC\%2Fdocuments\%2FRussian\%2FD67\&ei=3_k6U6uMJvHV4QS1IYDYAw\&us$\mathrm{g}=$ AFQjCNE3JAwAte0_6fFrJoiDoRp8183xoA

Orr, M. (2003). The Russian Ground Forces y Reform 1992-2002. Recuperado de https://www.google.ru/

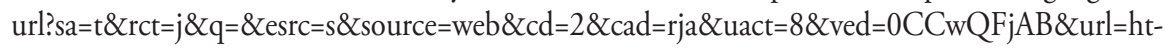
tp\%3A\%2F\%2Fda.mod.uk\%2FCSRC\%2Fdocuments\%2FRussian\%2FD67\&ei=3_k6U6uMJvHV4QS1IYDYAw\&usg=AFQjCNE3JAwAte0_6fFrJoiDoRp8183xoA

Pain, E. (julio-agosto, 2000). The Second Chechen War: The Information Component. Military Review. Recuperado de http://fmso.leavenworth.army.mil/documents/secchech/secchech.htm

Parchomenko, W. (1999). The State of Russia's Armed Forces and Military Reform. Parameters, (Winter 1999-2000), pp. 98-110.

Paterson, T. (1992). On Every Front: The Making and Unmaking of the Cold War. New York: W. W. Norton.

Persson, G. (2016). Russian Military Capability in a Ten-Year Perspective. New York: Taylor y Francis US.

Posen, B. (1986). The Sources of Military Doctrine. Ithaca: Cornell University Press.

Rodman, P. (1994). More Precious Than Peace: The Cold War and the Struggle for the Third World. New York: Scribner

Russell, J. (2005). Terrorists, Bandits, Spooks and Thieves: Russian Demonisation of the Chechens before and since 9/11. Third World Quarterly, 26(1), pp. 101-116. 
Serrano Álvarez, J. M. (2018). El paradigma de la guerra en el siglo XX. Revista Científica General José María Córdova, 16(23), 23-42. https://doi.org/10.21830/19006586.305

Suri, J. (2009). American Grand Strategy from the Cold War's End to 9/11. Orbis, 53(4), pp. 611-627.

Swaine, M. (2000). Does China have a Grand Strategy. Current History, 99(638), pp. 254-279.

The Moscow Times (2011). Sergei Ivanov. The Moscow Times. Recuperado de http://www.themoscowtimes.com/people/article/sergei-ivanov/433915.html

The New York Times, 2005. Chechen official puts death toll for 2 wars at up to 160,000. The New York Times. Recuperado de http://www.nytimes.com/2005/08/15/world/europe/15iht-chech.html?_r=0

The White House (1982). U. S. National Security Strategy: NSDD-32. Washington: Government of the United States of America.

The White House (1983). U. S. Relations with the USSR: NSDD 75. Washington: Government of the United States of America.

Thornton, R. (2011). Military modernization and the Russian ground forces. Carlisle, PA: Strategic Studies Institute, U. S. Army War College. Recuperado de http://www.strategicstudiesinstitute.army.mil/ pubs/display.cfm?pubID=1071

Trenin, D. (2016). The Revival of the Russian Military: How Moscow Reloaded. Foreign Affairs, 95(3), pp. 23-29.

Velasco, J. (2010). Neoconservatives in U. S. Foreign Policy under Ronald Reagan and George W. Bush. Baltimore: Johns Hopkins University Press.

Vendil, C. (2008). Russian Military Reform: A Failed Exercise in Defence Decision Making. New York, NY: Taylor y Francis US.

Vendil, C. (2009). Russian Military Reform: A Failed Exercise in Defence Decision Making. New York: Taylor y Francis US.

Weitz, R. (2010). Global Security Watch Russia: A Reference Handbook. Santa Barbara, California: ABC-CLIO.

Yizhou, W. (2007). China's National Interests. Beijing: New World Press.

Zhengyi, W. (2004). Conceptualizing Economic Security and Governance: China Confronts Globalization. The Pacific Review, 17(4), pp. 523-545. 